\title{
Shared and distinct mechanisms of iron acquisition by bacterial and fungal pathogens of humans
}

\author{
Mélissa Caza and James W. Kronstad* \\ The Michael Smith Laboratories, Department of Microbiology and Immunology, University of British Columbia, Vancouver, BC, Canada
}

\author{
Edited by: \\ Mathieu F. Cellier, Institut national \\ de la recherche scientifique, Canada \\ Reviewed by: \\ Philippe Delepelaire, Institut de \\ Biologie Physico-Chimique, France \\ Roland Strong, Fred Hutchinson \\ Cancer Research Center, USA \\ Simon C. Andrews, University of \\ Reading, UK

\section{*Correspondence:} \\ James W. Kronstad, The Michael \\ Smith Laboratories, University of \\ British Columbia, 2185 East Mall, \\ Vancouver, BC V6T 124, Canada \\ e-mail:kronstad@msl.ubc.ca
}

Iron is the most abundant transition metal in the human body and its bioavailability is stringently controlled. In particular, iron is tightly bound to host proteins such as transferrin to maintain homeostasis, to limit potential damage caused by iron toxicity under physiological conditions and to restrict access by pathogens. Therefore, iron acquisition during infection of a human host is a challenge that must be surmounted by every successful pathogenic microorganism. Iron is essential for bacterial and fungal physiological processes such as DNA replication, transcription, metabolism, and energy generation via respiration. Hence, pathogenic bacteria and fungi have developed sophisticated strategies to gain access to iron from host sources. Indeed, siderophore production and transport, iron acquisition from heme and host iron-containing proteins such as hemoglobin and transferrin, and reduction of ferric to ferrous iron with subsequent transport are all strategies found in bacterial and fungal pathogens of humans. This review focuses on a comparison of these strategies between bacterial and fungal pathogens in the context of virulence and the iron limitation that occurs in the human body as a mechanism of innate nutritional defense.

Keywords: heme, hemoglobin, transferrin, siderophores, iron, microbial pathogenesis

\section{INTRODUCTION}

Iron is an extremely versatile cofactor that is essential for many biochemical reactions in both mammalian hosts and pathogenic microbes. Ferrous $\left(\mathrm{Fe}^{2+}\right)$ and ferric $\left(\mathrm{Fe}^{+}\right)$iron, the biologically relevant forms, are found in prosthetic groups, such as iron-sulfur clusters and heme, that are incorporated into many metalloproteins (e.g., aconitase and cytochromes), where the iron serves as a biocatalyst or as an electron carrier. Iron is also found in many mono- and di-nuclear non-heme iron proteins like ferritin and ribonucleotide reductase. The redox potential of iron makes it especially useful for biological processes, in particular for oxidative phosphorylation where iron reduction/oxidation facilitates electron transfer in the respiratory chain. Moreover, iron is present in multiple proteins with diverse functions that include replication and repair of DNA, transport of oxygen, metabolism of carbon [e.g., via the tricarboxylic acid (TCA) cycle] and regulation of gene expression. Several reviews on the importance of iron in biological processes have appeared recently (Evstatiev and Gasche, 2012; Tandara and Salamunic, 2012; Dlouhy and Outten, 2013; Ilbert and Bonnefoy, 2013).

Because of its utility, iron is an essential element and an object of extreme competition between pathogens and their hosts. However, upon oxygenation of the Earth's atmosphere, the predominant form of iron switched from the relatively soluble ferrous state to the extremely insoluble ferric form at neutral $\mathrm{pH}$. In fact, ferric iron is oxidized and polymerized into insoluble polymers of ferric (oxy)hydroxide at $\mathrm{pH}$ 7.0, thus further limiting its biological accessibility (Griffiths, 1999; Ilbert and Bonnefoy, 2013). On the other hand, ferrous iron is quite toxic due to its propensity to react with oxygen to generate reactive oxygen species (ROS) via the Fenton and Haber-Weiss reactions. ROS can damage membrane lipids, proteins and DNA (Imlay, 2003). Therefore, iron acquisition, storage, and incorporation into proteins must be carefully managed by mechanisms that promote solubility, control the redox state, and avoid toxicity.

In this review, we discuss and compare selected examples of how pathogenic bacteria and fungi perform iron uptake in the context of competitive sequestration by host proteins. Detailed studies have been performed in a large number of bacterial species and we will focus on illustrative examples. For the fungi, we will describe iron acquisition systems in the three best-studied opportunistic pathogens. These are the mold Aspergillus fumigatus (a saprotroph that is also responsible for invasive pulmonary aspergillosis), the polymorphic fungus Candida albicans (the cause of skin or mucosal infections and invasive candidiasis), and the yeast Cryptococcus neoformans (the agent of cryptococcosis, a disease involving life-threatening meningoencephalitis). We have mainly focused our discussion on iron sources and uptake mechanisms in the context of virulence, with limited coverage of regulation. This is because many excellent reviews have summarized regulatory aspects of iron acquisition and homeostasis in bacteria, fungi and mammals (Andrews et al., 2003; Hentze et al., 2010; Cornelis et al., 2011; Schrettl and Haas, 2011; Wang and Pantopoulos, 2011; Pantopoulos et al., 2012; Philpott et al., 2012; Salvail and Masse, 2012; Kronstad et al., 2013).

\section{IRON DISTRIBUTION IN THE MAMMALIAN HOST: OPPORTUNITIES FOR MICROBIAL EXPLOITATION}

A large quantity of iron is potentially available to microbes upon infection of vertebrate hosts, although pathogens must extract 
this iron from a variety of proteins in blood, different cell types, and tissue locations. In fact, the average human adult contains $3-5 \mathrm{~g}$ of iron, the majority of which $(65-75 \%)$ is found in heme associated with hemoglobin within erythrocytes (red blood cells or RBCs) (McCance and Widdowson, 1937; Andrews, 2000). Each day, $20-25 \mathrm{mg}$ of iron is required to support the synthesis of hemoglobin. The daily intake of iron is very low (1-2 mg per day); therefore a considerable amount of iron is recycled each day mainly by macrophages. Macrophages recognize and phagocytose damaged or senescent RBCs, with the spleen playing a major role in recycling. Phagocytized RBCs are first degraded to extract heme and iron is subsequently released by heme oxygenase (HO-1) for reutilization in erythropoiesis. Hence, approximately $1 \mathrm{~g}$ of iron is stored in hepatocytes and macrophages of the liver (Kupffer cells) and spleen. A number of recent reviews have appeared that summarize iron homeostasis in humans (Bleackley et al., 2009; Evstatiev and Gasche, 2012; Ganz, 2012; Tandara and Salamunic, 2012).

Dietary iron is taken up in the intestine (duodenum and upper jejunum) either as ferrous iron [after reduction of ferric iron by the intestinal ferric reductase, duodenal cytochrome $\mathrm{B}$ (DcytB)], or as heme (McKie et al., 2001; Latunde-Dada et al., 2008; Evstatiev and Gasche, 2012). The ferrous iron is transported by divalent metal transporter 1 (DMT1), located at the apical membrane of enterocytes (Fleming et al., 1997; Gunshin et al., 1997). The mechanism of dietary heme uptake remains to be clarified. The heme carrier protein 1 (HCP1) was proposed as a heme receptor in duodenal enterocytes (Shayeghi et al., 2005); however, its primary role may be to transport folic acid rather than heme (Qiu et al., 2006). HRG-1, the heme responsive gene-1, was first identified in Caenorhabditis elegans as a heme importer (Rajagopal et al., 2008). The human homologue of HRG-1 appears to transport heme as well, but rather from the lysosome into the cytosol (Yanatori et al., 2010; Delaby et al., 2012). FLVCR2 (feline leukemia virus, subgroup C receptor 2) was also recently reported to mediate the endocytosis of heme by mammalian cells (Duffy et al., 2010). The availability of dietary iron to pathogens and the microbiota in the intestine is relevant to colonization, commensalism, and invasion, as demonstrated by recent studies with both bacterial and fungal pathogens (Chen et al., 2011; Kortman et al., 2012; Deriu et al., 2013).

Iron can also be found in blood upon the release of hemoglobin and heme from ruptured erythrocytes and enucleated erythroblasts. However, free hemoglobin is trapped by haptoglobin and taken up by hepatocytes or macrophages via the CD163 receptor (Kristiansen et al., 2001). Heme that is released into the bloodstream can also be bound by hemopexin, albumin, and high and low density lipoproteins (HDL and LDL) (Ascenzi et al., 2005). The hemopexin-heme complex is cleared by hepatocytes and macrophages via the CD91 receptor (Hvidberg et al., 2005). Plasma heme can also originate from the degradation of myoglobin and heme-containing enzymes such as catalases, peroxidases and cytochromes, and from myeloperoxidase secreted from neutrophils (Ascenzi et al., 2005). All these mechanisms promote iron recycling and also protect the host from iron toxicity.

Transferrin in the circulatory system can also potentially be exploited by microbes during bloodstream infections.
Approximately $2-3 \mathrm{mg}$ of iron is bound to partly saturated transferrin in plasma (Tandara and Salamunic, 2012). However, transferrin in serum is partially saturated (about 30-40\%) to limit the availability of free iron (Williams and Moreton, 1980; Aisen et al., 2001). The transferrin polypeptide has two homologous globular lobes that each binds one iron atom, and ferric iron is tightly bound at physiological $\mathrm{pH}\left(K_{a}\right.$ about $\left.10^{20} \mathrm{M}^{-1}\right)$ (Aisen and Brown, 1977). Consequently, the plasma concentration for free ferric iron is $\sim 10^{-24} \mathrm{M}$ (Otto et al., 1992). Transferrin delivers ferric iron to cells via the transferrin receptor (TfR1) expressed on almost every cell, and also by another receptor, TfR2, expressed in hepatocytes ( $\mathrm{Hu}$ and Aisen, 1978; Kawabata et al., 1999; Fleming et al., 2000). Iron-loaded transferrin bound to its receptor is endocytosed through a clathrin-dependent pathway, and acidification during endosome maturation dissociates ferric iron from transferrin; the iron-depleted complex is then recycled (Dautry-Varsat et al., 1983; Aisen, 2004; Steere et al., 2012). Subsequent reduction of iron to the ferrous form is achieved in endosomes by the Steap 3 (six-transmembrane epithelial antigen of the prostate 3) protein in erythrocytes and other Steap proteins in non-erythroid cells (Ohgami et al., 2005, 2006). Iron is exported from endosomes to the cytosol by DMT1 (Fleming et al., 1998).

Lactoferrin is a member of the transferrin family that is predominantly found in milk, but can also be present in mucosal secretions like tears and saliva, and in neutrophil granules (Evans et al., 1999). Like transferrin, lactoferrin can bind two atoms of iron, but it retains iron at a much lower $\mathrm{pH}(\sim 3.0)$ than transferrin ( 5.5) (Mazurier and Spik, 1980; Baker and Baker, 2004). Lactoferrin contributes to immunity by iron sequestration at sites of infection. Similarly, the host protein siderocalin (also called NGAL and lipocalin2) plays a role in the innate immune response against microbial pathogens by iron sequestration (Flo et al., 2004). It has been proposed that the small molecule 2,5dihydroxybenzoic acid, also known as gentisic acid, functions as a mammalian siderophore (a low molecular weight iron chelator) (Devireddy et al., 2010). This molecule is able to bind iron and it was proposed that it delivers the metal to cells via interaction with the siderocalin and the cell surface receptor 24p3R (Devireddy et al., 2005). However, binding studies contradict this hypothesis, since gentisic acid does not form high-affinity complexes with siderocalin and iron (Correnti et al., 2012). The interesting role of siderocalin and it physiological importance in mammalian iron homeostasis are yet to be defined; however, its function in the competition for iron with bacterial pathogens is better understood and described in more detail below in the discussion of siderophores.

Once iron is taken into a cell, it is stored in ferritins for later use or incorporated into metalloproteins in complexes with heme (e.g., catalase, cytochromes, hemoglobin and myoglobin), as mono and dinuclear iron (e.g., ribonucleotide reductase), or as Fe-S clusters (e.g., aconitase, succinate dehydrogenase) (Rouault and Tong, 2008; Dlouhy and Outten, 2013). Ferritins are ironstorage proteins composed of 24 subunits and are able to accumulate up to 4500 iron atoms (Fischbach and Anderegg, 1965; Hoare et al., 1975). These proteins are present in the cytoplasm, nucleus, and mitochondria of cells and also in plasma, and they release 
iron during iron deficiency via a mechanism involving lysosome acidification and autophagy (De Domenico et al., 2006; Asano et al., 2011). Iron can be exported from cells by ferroportin, a ferrous iron transporter (Donovan et al., 2000). Ferrous iron can be oxidized by hephaestin in intestinal enterocytes and by ceruloplasmin in macrophages, immune cells and other cell types, and loaded onto transferrin for subsequent distribution via the bloodstream (Curzon and O'reilly, 1960; Osaki et al., 1966; Yang et al., 1986; Vulpe et al., 1999). Iron homeostasis in humans is maintained by the major regulator hepcidin that binds to ferroportin and promotes its degradation. This triggers a series of event resulting in a loss of intestinal iron absorption and cellular iron efflux (Anderson et al., 2002; Nemeth et al., 2004). The regulation of iron homeostasis has been reviewed recently (Evstatiev and Gasche, 2012; Tandara and Salamunic, 2012; Finberg, 2013).

The trafficking of iron in mammalian host cells is summarized in Figure 1. This figure and the information outlined above define the range of target iron sources that microbes can potentially exploit to proliferate in a variety of host tissues. It is clear that iron homeostasis and availability are tightly controlled by binding proteins and that the competition for iron is therefore a key aspect of infectious diseases. The microbial strategies to compete for iron are outlined in the following sections.

\section{MICROBIAL STRATEGIES FOR IRON ACQUISITION FROM MAMMALIAN SOURCES}

Pioneering work by Schade and Caroline in 1944 revealed that high affinity iron binding proteins present in blood and egg whites are able to inhibit the growth of several bacterial species including Escherichia coli, as well as the yeast Saccharomyces cerevisiae (Schade and Caroline, 1944). They deduced that iron was too tightly bound to these proteins to be available to bacteria and yeast cells, thus inhibiting their growth. Importantly, growth could be restored by addition of iron, and this study was the first to establish a link between iron-related natural host resistance and microbial growth. Subsequently, Bullen et al. demonstrated that iron injection into guinea pigs considerably decreased the lethal dose of E. coli, thus suggesting an important role of iron in bacterial infection (Bullen et al., 1968). These and other studies led Kochan to propose the concept of "nutritional immunity," the phenomenon that host control of access to essential nutrients, including iron, could impact the survival and proliferation of microbial pathogens (Kochan, 1973). In response, successful pathogens can overcome nutritional immunity by efficiently acquiring iron within the host via four strategies that target specific iron sources: (1) iron acquisition from heme and hemecontaining proteins; (2) iron acquisition from transferrin, lactoferrin, and ferritin; (3) ferric iron acquisition by siderophores and; (4) uptake of ferrous iron. These strategies are described in the following sections.

\section{IRON ACQUISITION FROM HEME AND HEME-CONTAINING PROTEINS}

One strategy for microbes to obtain iron during infection of mammals is to target heme, hemoglobin, or complexes containing these molecules (e.g., haptoglobin-hemoglobin, hemopexinheme). This strategy requires access to host heme sources, and several pathogenic bacteria and fungi therefore secrete hemolysins to lyse red blood cells and release hemoglobin, and/or produce hemoglobin proteases to degrade the protein. Hemolysins have been characterized in Gram-negative bacteria, such as pathogenic E. coli ( $\alpha$-hemolysin HlyA, ClyA, Hpb, and EspC) (Felmlee et al., 1985; Otto et al., 1998; Ludwig et al., 2004; Drago-Serrano et al., 2006), Vibrio cholerae El-Tor (HlyA) (Stoebner and Payne, 1988) and Bordetella pertussis (CyaA) (Glaser et al., 1988), as well as in Gram-positive bacteria including Staphylococcus epidermis ( $\delta$-hemolysin Hdl) (Verdon et al., 2009) and Bacillus cereus (hemolysin BL) (Senesi and Ghelardi,
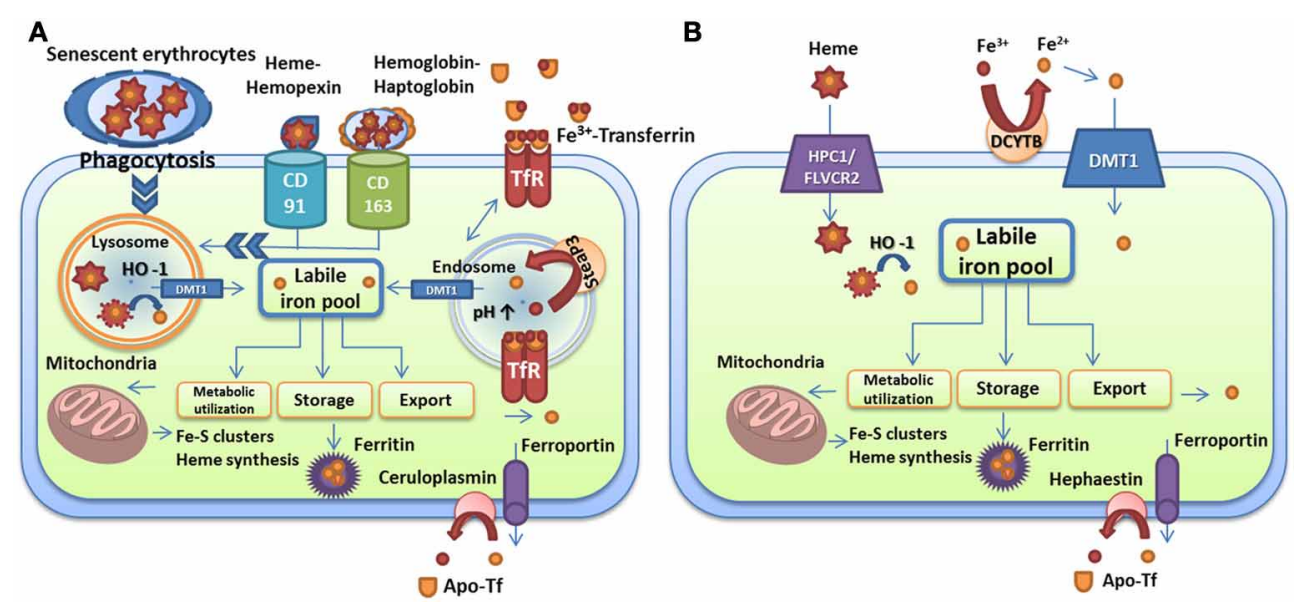

FIGURE 1 | Iron transport and homeostasis in human cells. (A) Iron recycling in macrophages via phagocytosis of senescent red blood cells, uptake of heme-hemopexin and hemoglobin-haptoglobin complexes, and iron-loaded transferrin. (B) Dietary iron and heme absorption by intestinal endocytes via DMT1 and the heme receptor HCP1/FLVCR2, respectively. Iron-loaded siderocalin can also be absorbed via the receptor $24 p 3 R$. Iron is extracted from these carriers by heme oxygenase in lysosomes or by reductases in endosomes and is used for metabolic processes (mitochondria, storage, or export). Export is performed by ferroportin in partnership with ceruloplasmin in macrophages and with hephaestin in intestinal cells. Iron is loaded on transferrin for distribution. The descriptions of the specific proteins are given in the text. 
2010). Fungi also produce hemolysins or have been reported to possess hemolytic activity. For example, the mold A. fumigatus secretes the hemolysin Asp which has hemolytic activity on chicken erythrocytes (Yokota et al., 1977). The polymorphic fungus $C$. albicans also possesses hemolytic activity but the yeast C. neoformans reportedly does not (Manns et al., 1994). Moreover, microbial pathogens have evolved two mechanisms to acquired iron from heme and heme-containing proteins: 1) direct uptake of heme and 2) use of hemophores (heme-binding proteins). These strategies have been extensively studied in numerous Gram-negative bacteria, while only a few examples are known in Gram-positive bacteria and in fungi. Iron acquisition strategies from heme and heme-containing proteins are illustrated in Figure 2 and described below.

\section{HEME UPTAKE IN BACTERIA \\ Gram-negative bacteria}

The direct uptake of heme by Gram-negative bacteria is a wellcharacterized strategy for iron acquisition. In general, heme uptake is achieved by recognition and binding to a specific receptor in the outer membrane $(\mathrm{OM})$. These surface receptors can directly bind heme and process its transport, but they are usually also able to bind heme-containing proteins like hemoglobin, haptoglobin-hemoglobin, hemopexin-heme, and myoglobin (Wandersman and Delepelaire, 2004). In that case, heme is extracted from these complexes and transported into the periplasm in a TonB-dependent manner (in Gram-negative bacteria). TonB-ExbB-ExbD is an energy-transducing complex that energizes outer membrane receptors to facilitate translocation of specific cargo (Braun and Braun, 2002). The majority of the outer membrane heme uptake receptors, as well as siderophore transporters and some transferrin/lactoferrin receptors (see below),

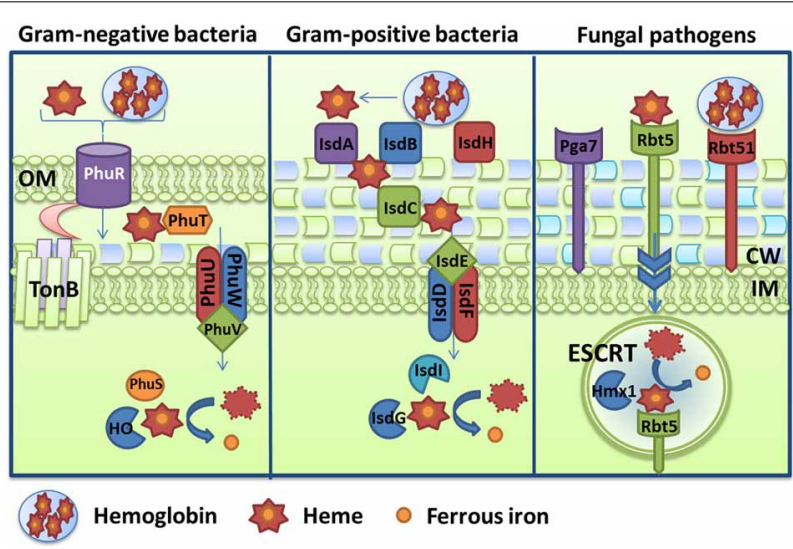

FIGURE 2 | Diagrams of hemoglobin and heme uptake and utilization. Mechanisms are depicted for the Gram-negative bacterium Pseudomonas aeruginosa via the Phu system, and for the Gram-positive bacterium Staphylococcus aureus via the Isd system. For comparison, the scheme in the fungal pathogen Candida albicans is also illustrated and components include the receptors Rbt5, Rbt51, and Pga7. A schematic is also included to depict endocytosis (via ESCRT functions) and processing (with the heme oxygenase $\mathrm{Hm} \times 1$ ). Additional details about the specific proteins are given in the text. are members of the TonB-dependent outer transporter (TBDT) family. Two unique domains are found in the TBDT fold: (1) a $\beta$-barrel with 22 anti-parallel strands and an internal diameter of 35-47 $\AA$ and (2) an N-terminal cork domain that blocks the internal space and prevents passive diffusion through the barrel (Ferguson and Deisenhofer, 2002). Furthermore, two His residues, or in some cases one Tyr residue, are required for heme transport across the barrel. Two conserved amino acid motifs (FRAP and NPNL) have also been identified on the extracellular loop containing one of the His residues (Bracken et al., 1999; Hagan and Mobley, 2009). The NPNL motif plays a role in binding heme due to its surface exposed location, whereas the FRAP motif is likely involved in heme transport across the cell membrane because it is buried inside the barrel (Liu et al., 2006). Once in the periplasm, heme is bound to a heme transport protein (HTP) and delivered to an ABC transporter in the inner membrane. Heme is then transported into the cytoplasm in an ATP-dependent fashion with subsequent degradation and iron release by bacterial heme oxygenases (Anzaldi and Skaar, 2010). The expression of the majority of these systems is controlled by the bacterial "ferric uptake regulator" protein Fur. Fur is a dimeric DNA-binding repressor that uses ferrous iron as a co-factor. Fur plays a central role in the bacterial response to iron starvation as it binds to promoter regions of iron-regulated genes at a so-called "fur box" and represses their expression under iron-replete conditions. Upon iron limitation, the Fur-Fe(II) complex dissociates from the DNA, thereby allowing transcription of iron-regulated genes (Hantke, 1981; Bagg and Neilands, 1987; De Lorenzo et al., 1987). Other proteins can also participate in the regulation of these systems under different conditions.

One of the two heme uptake system in Pseudomonas aeruginosa is illustrated in Figure 2 as an example. This system is encoded by the phuR-phuSTUVW genes, and PhuR is the outer membrane receptor, PhuT is the HTP, PhuUVW is the inner membrane $\mathrm{ABC}$ transporter and $\mathrm{PhuS}$ is an intracellular heme trafficking protein that delivers heme to the heme oxygenase ( $p a-$ HO, PigA, or HemO) (Ochsner et al., 2000; Ratliff et al., 2001; Lansky et al., 2006). This system facilitates the uptake of heme and the use of heme from hemoglobin since mutation of any component reduces growth on these iron sources (Ochsner et al., 2000). However, the specific mechanism of heme extraction from hemoglobin at the cell surface by PhuR or another protein is currently unknown. The amino acid sequence of PhuR shares similarity with several heme and hemoglobin receptors, such as HutA from V. cholerae (Henderson and Payne, 1994), ChuA from E. coli O157:H7 (Torres and Payne, 1997) and HmuR from Y. pestis (Hornung et al., 1996). Furthermore, three conserved motifs were identified in the amino acid sequence of PhuR, including a "TonB box," and this strongly suggests a TonB-dependent translocation mechanism (Ochsner et al., 2000). Once heme is translocated into the periplasmic space, it is bound by PhuT. This heme transport protein binds heme and protoporphyrin IX at a ratio of 1:1 with high affinity $\left(\mathrm{K}_{\mathrm{d}} \sim 1.2\right.$ and $14 \mathrm{nM}$, respectively) (Tong and Guo, 2007). It is believe that PhuT delivers heme to the inner membrane transporter PhuUVW, although direct transfer of heme has not been demonstrated. Once in the cytoplasm, heme is bound by PhuS and delivered to the heme oxygenase HemO (Lansky et al., 
2006). Protein-protein interaction studies identified a mechanism in which a heme-dependent conformational switch in PhuS drives heme release to HemO in a unidirectional fashion (Bhakta and Wilks, 2006; O’Neill et al., 2012). HemO is a $\delta$-regioselective heme oxygenase that cleaves heme and produces biliverdin IX- $\beta$ and $-\delta$ (Ratliff et al., 2001). Interestingly, the metabolic flux of heme uptake is driven by HemO, since mutation of the heme oxygenase results in loss of heme uptake and no production of biliverdin (Barker et al., 2012; O'Neill and Wilks, 2013). Expression of phuR and the phuSTUVW operon is controlled by the Fur regulator and two "Fur boxes" were identified by DNase footprinting (Ochsner et al., 2000).

Other similar heme and hemoglobin uptake systems have been characterized in several pathogenic Gram-negative bacteria including Yersinia pestis (HmuRSTUV) (Hornung et al., 1996; Thompson et al., 1999), Yersinia enterocolitica (HemRSTUV) (Stojiljkovic and Hantke, 1992, 1994), Vibrio cholerae (HutABCD) (Occhino et al., 1998) and the uropathogenic E. coli strain CFT073 (ChuA-Hma-DppABCDF) (Torres and Payne, 1997; Torres et al., 2001; Letoffe et al., 2006; Hagan and Mobley, 2009). Expression of the outer membrane receptors of these systems is regulated by Fur, they are all members of the TBDT family and they possess conserved FRAP and NPNL motifs. Site-direct mutagenesis of the TBDT HemR from $Y$. enterocolitica identified two conserved His residues as being required for heme transport through the receptor pore, while binding activity of heme was not affected (Bracken et al., 1999). The Hma receptor of E. coli requires a cell-surface exposed Tyr residue for heme use rather than the conserved His residues (Hagan and Mobley, 2009). The contributions of these systems to virulence have been evaluated for some of these bacteria. For example, virulence was tested for mutants lacking the $\mathrm{Hmu}$ and ChuA-Hma systems of $Y$. pestis and E. coli, respectively. Heme acquisition via the receptors ChuA and Hma in uropathogenic E. coli contributes to disease in mice, while the Hmu system in $Y$. pestis does not (e.g., when inoculated by subcutaneous or retro-orbital injection), presumably due to redundancy in iron acquisition systems for this species (Thompson et al., 1999; Torres et al., 2001; Hagan and Mobley, 2009).

Other systems are present in gram-negative bacteria for the use of hemoglobin as a sole source of iron. For example, Haemophilus influenzae type $\mathrm{B}$ ( $\mathrm{Hib})$ is able to use hemoglobin via three TonB-dependent cell surface receptors, HgpA, HgpB, and HgpC, that bind hemogloblin and hemoglobin-haptoglobin (Jin et al., 1996; Morton et al., 1999). Deletion of the $h g p$ genes abolishes growth on hemoglobin-haptoglobin as a sole heme/iron source, although only a partial reduction occurred in the ability to use hemoglobin (Morton et al., 1999). The heme utilization protein Hup is responsible for this residual heme uptake activity from hemoglobin, since mutation of all of the hgp and hup genes resulted in a severe growth defect in the presence of low concentrations of hemoglobin or heme as the only iron source (Morton et al., 2004). It is believe that heme is extracted from hemoglobin at the cell surface by these receptors, although this activity has not yet been demonstrated. Nevertheless, once heme is translocated into the periplasm, it is taken up by the lipoprotein HbpA (Hanson and Hansen, 1991; Hanson et al., 1992b).
Deletion of the $h p b A$ gene in Hib resulted in growth diminution in the presence of low concentrations of heme, heme-hemopexin, and heme-albumin, but not in the presence of hemoglobin or hemoglobin-haptoglobin. These data indicate that $H$. influenzae may possess other periplasmic heme transporters in addition to HbpA (Morton et al., 2007b, 2009a). It has been proposed that HbpA delivers heme to the DppBCDF membrane transporter (Morton et al., 2009b), although several homologues of heme $\mathrm{ABC}$ transporters (SapACBDF and OppABCDF) have been discovered and may participate in heme transport in different strains of H. influenzae (Fleischmann et al., 1995; Mason et al., 2011). Nothing is known about how iron is extracted from heme once it enters the cytoplasm. Mutations in the hgp, hup, $h p b A$ and hel (encoding lipoprotein $e(\mathrm{P} 4)$, another periplasmic heme binding protein) genes had no impact on virulence in a bacteremia model with 5-day old rats (Morton et al., 2004, 2007a). However, mutation of the $h g p, h b p A$, and hel genes in Hib caused a significantly lower rate of bacteremia relative to the wild-type strain in a 30day old rat model of infection (Seale et al., 2006; Morton et al., 2007b, 2009a). The level of plasma hemopexin and haptoglobin increases with age in rats, which may explain the requirement of different heme and hemoprotein acquisition systems for the virulence of $H$. influenza in older rats (Seale et al., 2006). This system of heme acquisition from hemoglobin is similar to the heme acquisition system from $P$. aeruginosa in that heme is transported into the cytoplasm by specific TonB-dependent outer membrane receptors, periplasmic proteins, and inner membrane ABC transporters.

Outer membrane receptors have also been identified that facilitate the use of hemoglobin. For example, Neisseria meningitidis is able to bind hemoglobin but not heme through the outer membrane receptor HmbR. This protein, like many outer membrane receptors for heme and iron acquisition systems, requires a functional TonB system and is regulated by Fur. HmbR functions by binding to hemoglobin and removing heme for subsequent translocation into the periplasm, and an NPNL motif has a possible role in heme removal. The cork domain of $\mathrm{HmbR}$ is also involved in heme passage to the periplasm (Perkins-Balding et al., 2003). Furthermore, an hmbR mutant is attenuated in an infant rat model for meningococcal infection, indicating that the use of hemoglobin as an iron source is important for $N$. meningitidis virulence (Stojiljkovic et al., 1995). N. meningitidis and Neisseria gonorrhoeae also possess a distinct bipartite TonBdependent receptor for hemoglobin designated HpuAB. HpuB is an outer membrane receptor and HpuA encodes a lipoprotein, and together they transport heme from hemoglobin and the hemoglobin-haptoglobin complex. Expression of the $h p u A B$ operon is regulated by iron and Fur (Lewis and Dyer, 1995; Lewis et al., 1997; Turner et al., 1998; Rohde et al., 2002). Both receptors $(\mathrm{HmbR}$ and $\mathrm{HpuAB}$ ) are also subject to phase variation (Lewis et al., 1999) and the presence of either HmbR or HpuAB was found to be highly correlated with clinical isolates causing disease, suggesting a role in virulence for iron acquisition from hemoglobin (Tauseef et al., 2011). It is believe that these bacteria employ phase variation to more effectively adapt to the hostile environment of the host. So far, nothing is known about the intracellular transport of heme into the cytoplasm of these bacteria, 
although the process likely involves an ABC transporter. Similarly to the heme uptake system of $P$. aeruginosa, a heme oxygenase, HemO has been identified in Neisseria species and is required for the degradation of heme into ferric iron, biliverdin, and $\mathrm{CO}$ (Zhu et al., 2000a,b).

\section{Gram-positive bacteria}

Heme acquisition systems in Gram-positive bacteria share properties with those in Gram-negative bacteria in that they consist of cell surface receptors for heme, cell wall chaperone proteins that facilitate internalization of heme, $\mathrm{ABC}$ transporters that perform membrane translocation and heme oxygenase activities to release iron from heme. The HtaAB-HmuOTUV heme acquisition system identified in Corynebacterium diphtheriae illustrates the organization of one such system. Cell surface exposed HtaA binds hemoglobin and transfers heme to HtaB (Allen and Schmitt, 2009). Heme is believed to be transported inside the cell by the activities of the cell wall protein HmuT, the ATP transporter HmuUV and the cytoplasmic heme oxygenase $\mathrm{HmuO}$ that extracts the iron (Wilks and Schmitt, 1998; Drazek et al., 2000; Allen and Schmitt, 2009, 2011). Recently, another heme/hemoglobin system was identified in C. diphtheriae (Allen et al., 2013). Specifically, three proteins that are exposed on the cell surface, ChtA, ChtB, and ChtC, are able to bind heme and hemoglobin, with ChtA showing the highest affinity. A mutant lacking both $c h t B$ and $h t a B$ had significantly impaired iron use from heme, indicating a contribution of both systems for heme iron acquisition. No evaluations of virulence have been reported for these systems. As in Gram-negative bacteria, it appears that multiple heme acquisition systems are generally present in the Gram-positive bacteria characterized to date (i.e., with several surface receptors and $\mathrm{ABC}$ transporters).

\section{USE OF HEMOPHORES BY BACTERIA Gram-negative bacteria}

Hemophores are secreted proteins with the ability to bind heme and/or heme-containing proteins in the extracellular environment. This definition has recently been expanded to include any surface-exposed (or secreted) protein involved in the transfer of heme to a transporter for import (Wandersman and Delepelaire, 2012). A hemophore system was first discovered in 1994 in Serratia marcescens and others have been identified subsequently in Gram-negative and Gram-positive bacteria (Letoffe et al., 1994a; Wandersman and Delepelaire, 2012). As described below, a candidate hemophore has also recently been described in the fungal pathogen C. neoformans (Letoffe et al., 1994a; Cadieux et al., 2013). The hemophore system in S. marcescens (Has) includes the secreted HasA protein that is able to extract heme from hemoglobin, hemopexin and myoglobin (Letoffe et al., 1994a; Wandersman and Delepelaire, 2012). HasA is secreted by the export complex HasDEF, where HasD is an ATPase, HasE is a membrane fusion protein and $\mathrm{HasF}$ is an outer membrane protein (Letoffe et al., 1994b). Heme is transferred from hemoproteins to HasA by a passive mechanism due to higher affinity of HasA for heme, without protein-protein complex formation (Letoffe et al., 1999). HasA interacts with and delivers heme to the specific outer membrane receptor HasR (Izadi-Pruneyre et al., 2006).
HasR can perform the uptake of heme from hemoglobin alone, but the process is 100 times more efficient with the participation of HasA (Arnoux et al., 2000). The determination of the structure of the HasR receptor revealed a cork and a $\beta$-barrel organization like other heme receptors, with two conserved His residues being important for heme binding (Izadi-Pruneyre et al., 2006; Krieg et al., 2009). This receptor actively transports heme with the help of HasB, a TonB orthologue that functions specifically with HasR (Benevides-Matos et al., 2008). After heme transfer from HasA to HasR, apo-HasA remains bound to HasR. The release of apo-HasA from the receptor is performed in an energy-driven process by HasB (Paquelin et al., 2001). This recycling process for HasA is only observed in the presence of heme, which is also required for the induction of has $B$ expression (Rossi et al., 2003; Wandersman and Delepelaire, 2012). The Has system is negatively regulated by iron and Fur, and positively regulated by a sigma and anti-sigma (HasI and HasS) signaling cascade triggered by hemeloaded hemophore binding to HasR (Rossi et al., 2003; Cwerman et al., 2006). Systems with similarity to Has have been reported in $P$. aeruginosa (Letoffe et al., 1998), P. fluorescens (Idei et al., 1999), and Y. pestis (Rossi et al., 2001). The contribution of the Has system to the virulence of $Y$. pestis has been assessed in a mouse model of bubonic plague and no role was found, even in the absence of the Hmu system for heme uptake (Rossi et al., 2001).

H. influenza type $\mathrm{b}(\mathrm{Hib})$ also produces a hemophore system (Hxu) that is synthesized from the $h x u C B A$ gene cluster. The hemophore HxuA is able to bind the human heme-hemopexin complex and to release heme into the medium. HxuA is either anchored to the cell surface or partially released into culture medium depending on the strain (Wong et al., 1995). Unlike HasA, HxuA does not directly bind heme, but rather it interacts with hemopexin and interferes with its ability to sequester heme (Hanson et al., 1992a; Fournier et al., 2011). Free heme is then internalized by the TonB-dependent outer membrane receptor $\mathrm{HxuC}$, while $\mathrm{HxuB}$ is involved in secretion of HxuA (Cope et al., 1995). It was also reported that $\mathrm{HxuC}$ is involved in residual use of heme from hemoglobin, as seen in an $h g p$ triple knockout mutant, and in the direct use of heme from heme-albumin complexes. (Cope et al., 2001; Morton et al., 2007a). Moreover, deletion of the $h x u A B C$ genes significantly impaired the virulence of the strain in a 5-day-old rat model of bacteremia, but not in a 30-day old rat model, suggesting that these age related differences may be related to changes in levels of host heme-binding proteins during the development of the rat (Morton et al., 2007a). Subsequent heme transport across the inner membrane is likely to be performed by various $\mathrm{ABC}$ transporters as previously discussed.

Similar to HpuAB from Neisseria species, a bipartite receptor for heme has been described for Porphyromonas gingivalis. In this bacterium, the TonB-dependent heme receptor HmuR mediates heme uptake with the help of a heme-binding lipoprotein HmuY (Simpson et al., 2000; Olczak et al., 2008; Wojtowicz et al., 2009). HmuY has low affinity for heme but the proteolytic activity of secreted proteases (gingipains) on host heme-containing proteins facilitates heme release. For example, it has been demonstrated that HmuY can extract heme from hemoglobin after pre-treatment with gingipains (Olczak et al., 2001; Smalley et al., 
2007, 2011). In fact, R-gingipains cleave hemoglobin to allow oxidation from ferrous to ferric iron thus facilitating release of heme and subsequent degradation of globin by K-gingipain. Free heme is then bound by HmuY. HmuY was proposed to be a hemophorelike protein because it was found either attached to the outer membrane or release in the supernatant. This release is dependent on proteolytic cleavage by gingipains (Wojtowicz et al., 2009). Once heme is bound to HmuY, it is transferred to HmuR for uptake. As with other outer membrane receptors, HmuR has two conserved His residues and the NPDL motif for heme binding and utilization (Liu et al., 2006). The $h m u Y$ and $h m u R$ genes are regulated by the transcriptional activator PG1237 and are part of a larger locus (hmuYRSTUV) (Wu et al., 2009). The hmuSTUV genes may be responsible for heme transport to the cytoplasm. HmuS has sequence similarity to the cobN/Mg chelatase, HmuT and $\mathrm{HmuU}$ are similar to permeases and $\mathrm{HmuW}$ is annotated as an ATP-binding protein involved in hemin import (Lewis et al., 2006). Further studies are required to investigate these roles.

\section{Gram-positive bacteria}

The Isd (iron regulated surface determinant) system found in Staphylococcus aureus is one of the best-characterized mechanisms of iron acquisition from heme in Gram-positive bacteria. As illustrated in Figure 2, the Fur-regulated Isd machinery is composed of four cell wall-anchored proteins (IsdABCH), two cell wall sortases (SrtA and SrtB), a membrane transporter (IsdDEF) and two cytoplasmic heme oxygenases (IsdG and IsdI) (Mazmanian et al., 2003). Cell surface exposed IsdA binds heme, IsdB binds hemoglobin and heme, and IsdH binds heme, hemoglobin, haptoglobin and the complex of hemoglobinhaptoglobin (Dryla et al., 2003, 2007). Once heme is extracted by $\mathrm{IsdH}$ or IsdB, it is transferred unidirectionally to either IsdA or IsdC. Transfer can also occur from IsdA to IsdC, and bidirectionally between $\mathrm{Isd} \mathrm{H}$ and $\mathrm{Is} \mathrm{dB}$. As well, IsdC transfers heme unidirectionally to the lipoprotein IsdE (Liu et al., 2008; Muryoi et al., 2008; Zhu et al., 2008). The IsdABCH proteins in S. aureus have been structurally characterized and found to all possess one or more NEAT domains. The NEAT domain is a poorly conserved 120 amino acid region that is encoded in variable numbers in genes located in the vicinity of putative siderophore transporter genes; NEAT therefore stands for near transporter (Andrade et al., 2002). NEAT domains can bind heme, hemoglobin, or hemoglobin-haptoglobin. As an example, IsdH possesses three NEAT domains (N1, N2, and N3) and it has been demonstrated that $\mathrm{N} 1$ and $\mathrm{N} 2$ bind hemoglobin and hemoglobin-haptoglobin, whereas N3 binds heme (Pilpa et al., 2009). It is thought that the transfer of heme across the cell wall of $S$. aureus occurs by protein-protein interactions that shuttle heme from one NEAT domain to another until the membrane is reached (Wandersman and Delepelaire, 2012). The heme molecule is believed to be transported across the inner membrane via the action of the ABC transporter IsdDEF. However, it has been shown that an isdDEF mutant does not significantly reduce heme use, suggesting that another $\mathrm{ABC}$ transporter might be present in $S$. aureus (Mazmanian et al., 2003). Nonetheless, iron is then released in the cytoplasm by degradation via the action of IsdG and IsdI, which have similarity to monooxygenases (Wu et al., 2005). Virulence assays revealed that an is $d B$ mutant, but not an isdH mutant, showed reduced virulence in a murine abscess model of disease (Torres et al., 2006).

The Isd system has also been identified in several Grampositive bacteria including Streptococcus pyogenes and Bacillus anthracis (Maresso et al., 2006; Nygaard et al., 2006). In the latter species, the Isd system is composed of three genes (is $d X 1$, $i s d X 2$, and isdC) that encode proteins with one or more NEAT domains. It was shown that IsdX1 and IsdX2 are secreted proteins that extract heme from hemoglobin and deliver it to cell wallbound IsdC (Fabian et al., 2009). The IsdX1 and IsdX2 proteins do not possess a cell-wall anchoring motif, and they are therefore thought to be secreted hemophores (Maresso et al., 2008). So far, it is unclear how heme is transported into the cell for B. anthracis. A new hemophore, Hal, has also been discovered recently in this bacterium (Balderas et al., 2012). Hal contains one NEAT domain that binds heme, the protein has several leucine-rich repeats and is proposed to be covalently coupled by a sortase to the cell wall via its C-terminal Gram-positive bacterium anchor (GPA). Deletion of hal resulted in a growth defect on heme or hemoglobin as the sole iron source (Balderas et al., 2012). Recently, another iron regulated leucine-rich surface protein (IlsA) was identified in Bacillus cereus. This protein has a conserved NEAT domain and directly binds heme. Inactivation of ils $A$ decreases the ability of the bacterium to grow in the presence of hemoglobin, heme, and ferritin, indicating a role in iron acquisition for IlsA. Moreover, the ils $A$ mutant showed a reduction in growth and virulence in an insect model, suggesting an important role for iron acquisition in disease caused by B. cereus (Daou et al., 2009).

A similar heme/hemoglobin uptake system (Shp-Shr-HtsABC) was found in Streptococcus pyogenes, where HtsABC encodes an ABC transporter, Shp binds heme on the cell surface and Shr binds hemoglobin and the hemoglobin/haptoglobin complex (Lei et al., 2002, 2003; Bates et al., 2003). Furthermore, the direct transfer of heme from hemoglobin by Shr to Shp has been demonstrated ( $\mathrm{Lu}$ et al., 2012), and further characterization of Shp revealed two NEAT domains, a series of leucine-rich repeats and the absence of a cell wall-anchoring motif. It was also demonstrated that Shr spans the cell wall and is exposed to the extracellular environment, reminiscent of the Hal protein of $B$. anthracis (Fisher et al., 2008; Ouattara et al., 2010).

\section{Mycobacterium tuberculosis}

M. tuberculosis is known to acquire iron from transferrin and lactoferrin through secretion of the siderophores mycobactin and exochelins (Gobin and Horwitz, 1996). However, a pathway of heme utilization involving a secreted hemophore (Rv0203) and two trans-membrane proteins, MmpL11 and MmpL13, has been discovered recently. Mutation of either $r v 0203$ or mmpL11 significantly reduces growth on heme or hemoglobin as a sole iron source, while mutation of $m m l p 13$ was unsuccessful and the gene may be essential (Tullius et al., 2011). It also has been shown that Rv0203 binds heme with a similar affinity constant to the heme binding proteins PhuS and HmuT from P. aeruginosa and Y. pestis, respectively (Owens et al., 2012). Upon binding, Rv0203 rapidly transfers heme to either of the inner membrane transporters MmpL11 and MmpL13 (Owens et al., 2013). 


\section{HEME UPTAKE BY FUNGI}

Much less is known about heme use by pathogenic fungi compared with bacterial pathogens. The ability to utilize heme and hemoglobin as an iron source by $C$. albicans was first described in 1992 (Moors et al., 1992). It was initially demonstrated that $C$. albicans binds erythrocytes via complement-receptor-like molecules (Moors et al., 1992). Subsequently, it was found that C. albicans possesses a hemolytic factor described as a secreted mannoprotein, although further characterization is needed for this factor (Watanabe et al., 1999). Nevertheless, the uptake of hemoglobin is mediated by specific receptors exposed on the surface of $C$. albicans, as illustrated in Figure 2. The first two heme/hemoglobin receptors to be identified were Rbt5 and Rbt51. Both of these are extracellular, glycosylphophatidylinositol (GPI)-anchored proteins and they harbor a conserved CFEM domain that may be involved in heme binding (Weissman and Kornitzer, 2004). CFEM domains are composed of eight cysteine residues of conserved spacing and they are found in a number of fungal membrane proteins (Kulkarni et al., 2003). Three other members of the hemoglobin-receptor family (Csa1, Csa2, and Pga7) have been identified based on the presence of the CFEM domain (Almeida et al., 2009). Rbt51 is sufficient by itself to confer the ability to use hemoglobin on $S$. cerevisiae, while a mutant of RBT5 also showed a strong reduction of heme and hemoglobin use by C. albicans (Weissman and Kornitzer, 2004). Furthermore, Rbt5 facilitates the rapid endocytosis of hemoglobin into vacuoles in C. albicans cells. This endocytic process requires Myo5, a type I myosin that may be involved in endocytic vesicle scission, CaSla2, which is an actin-binding protein also required for endocytosis, an active vacuolar ATPase, and a member of the HOPS complex (CaVps41) (Weissman et al., 2008). Components of the ESCRT (endosomal sorting complex required for transport) system are also involved in the utilization of hemoglobin. ESCRT complex proteins are generally involved in transporting membrane proteins to the multivesicular body compartment and from there to the vacuole, where proteins are degraded (Hurley and Emr, 2006). Therefore, it was interesting that the ESCRT components are involved in heme/hemoglobin utilization, and that individual mutants of $C$. albicans (i.e., vps2, vps23, vps24, vps38, vps36 and $s n f 7$ ) show a growth delay in the presence of hemoglobin (Weissman et al., 2008). It is not clear how heme and hemoglobin are processed upon Rbt5 binding and endocytosis, but it has been proposed that acidification of the vacuole might be sufficient to extract heme from hemoglobin. Heme degradation by the heme oxygenase CaHmxl may occur in the vacuole or in the cytosol via transport of the heme molecule by a vacuolar transporter (Pendrak et al., 2004; Weissman et al., 2008). Importantly, $\mathrm{CaHmx1}$ is required for full virulence in a mouse model of disseminated candidiasis (Navarathna and Roberts, 2010).

The pathogenic yeast $C$. neoformans is also able to grow on hemoglobin and heme as sole iron sources (Jung and Kronstad, 2008). C. neoformans secretes a $43 \mathrm{KDa}$ serine proteinase that degrades hemoglobin and other substrates, although further characterization of this proteinase is needed (Yoo Ji et al., 2004). Information is starting to accumulate about heme use by $C$. neoformans. For example, an Agrobacterium-mediated T-DNA insertion screen for mutants with reduced growth on heme identified the ESCRT-I protein Vps23 as being important for iron acquisition from heme. Deletion of $v p s 23$ resulted in growth defect on heme presumably due to a defect in endocytosis and proper sorting of the heme cargo ( $\mathrm{Hu}$ et al., 2013). Recently, the first candidate hemophore in fungi was described in C. neoformans. This mannoprotein, Cig1, was shown to support iron acquisition from heme and to make a contribution to virulence in a mouse model of cryptococcal disease (Cadieux et al., 2013). However, the contribution of Cig1 to virulence was only evident in a mutant that also lacked a reductive, high affinity uptake system (described further below).

It is likely that other pathogenic fungi are able to use heme and hemoproteins. For example, the dimorphic pathogen Histoplasma capsulatum uses heme as a sole source of iron via a putative cellsurface receptor, although further studies are needed to elucidate the mechanism of heme uptake (Foster, 2002). It is also known that some important fungal pathogens, such as A. fumigatus, lack the ability to use heme as an iron source (Eisendle et al., 2003; Schrettl et al., 2004; Haas, 2012).

\section{IRON ACQUISITION FROM TRANSFERRIN, LACTOFERRIN AND FERRITIN DIRECT ACOUISITION OF IRON FROM TRANSFERRIN AND LACTOFERRIN IN BACTERIA}

Several bacterial pathogens can utilize non-heme, ironcontaining proteins like transferrin, lactoferrin, and ferritins as sources of iron. As illustrated in Figure 3, the Gram-negative bacteria N. meningitidis and N. gonorrhoeae possess the receptors $\mathrm{TbpAB}$ and $\mathrm{LbpAB}$ that mediate the uptake of ferric iron from transferrin and lactoferrin, respectively (Cornelissen et al., 1992; Biswas and Sparling, 1995). The TbpAB system consists of two transferrin-binding proteins expressed from a biscistronic operon regulated by Fur and encoding the TonB-dependent protein TbpA and the lipoprotein $\mathrm{TbpB}$ that acts as a co-receptor (Ronpirin et al., 2001). TbpA binds apo and holo-transferrin with similar affinities, whereas $\mathrm{TbpB}$ only binds preferentially to iron-containing transferrin (Cornelissen and Sparling, 1996; Boulton et al., 1998). TbpA is able to extract iron from transferrin in the absence of its co-receptor, but the process is considerably more efficient in the presence of $\mathrm{TbpB}$. In fact, it has been estimated that TbpB helps to internalize about half of the iron obtained from transferrin and also participates in the dissociation of apo-transferrin from the cell surface (Anderson et al., 1994; Derocco et al., 2009). The affinities for transferrin are distinct for TbpA and $\mathrm{TbpB}$, and for the combined receptor $(\mathrm{Tbp} \mathrm{AB})$, which suggests that formation of the dual receptor results in unique characteristics in the interaction with transferrin (Cornelissen and Sparling, 1996). Upon transferrin binding, TbpB forms a transient triple complex with TbpA. TbpA catalyzes a conformational change that leads to iron release and dissociation of apo-transferrin with the help of the TonB complex. TbpA is a TBDT protein and the conformational change moves the cork domain allowing the formation of a transient docking site for iron inside the $\beta$-barrel and transfer to the periplasmic ferric binding protein FbpA (Noinaj et al., 2012a,b). FbpA then initiates transport into the cytosol (Siburt et al., 2009). 


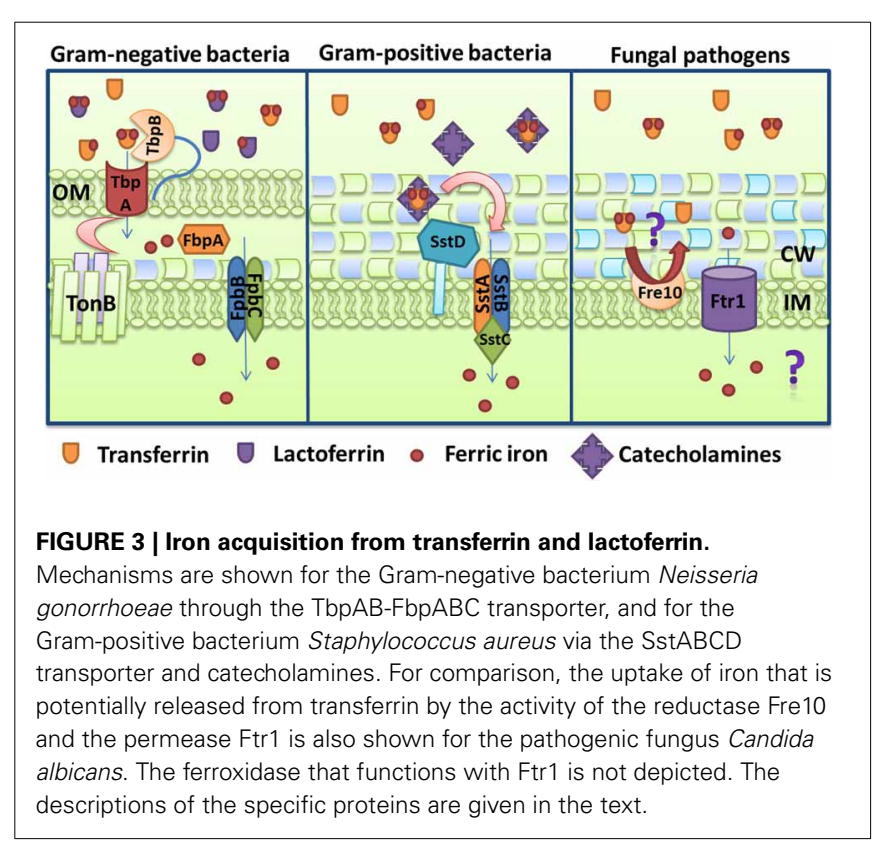

FbpA is also known as the bacterial transferrin due to its similarities in structure and function to human transferrin (Parker Siburt et al., 2012). The $f b p A B C$ operon encodes an ABC transport system, where $\mathrm{FbpB}$ is a permease and $\mathrm{FbpC}$ is a nucleotidebinding protein that provides energy to transport iron across the cytoplasmic membrane (Adhikari et al., 1996; Strange et al., 2011). The FbpABC system is also involved in transport of iron from lactoferrin but is not required for the acquisition of iron from heme and hemoglobin (Khun et al., 1998). The FbpABC transporter is also required for the transport of xenosiderophores (i.e., siderophores such as enterobactin and salmochelin S2 from other microbes) in a TonB-independent fashion (see below) (Strange et al., 2011). Virulence was assessed in a murine model of $N$. meningitidis bacteremia, and both a $t b p A t b p B$ mutant and a $t b p A$ mutant are avirulent in mice suggesting a role for iron acquisition through transferrin in disease (Renauld-Mongenie et al., 2004). A $t b p B$ mutant was as virulent as the wild-type strain. Importantly, a transferrin receptor mutant $(\Delta t b p A \Delta t b p B)$ for $N$. gonorrhoeae was unable to initiate urethritis in human volunteers, demonstrating that a bacterial iron acquisition system is an essential virulence factor for human infection (Cornelissen et al., 1998). This bipartite receptor mechanism of iron acquisition from transferrin and lactoferrin is reminiscent of the heme bipartite receptor HupAB in Neisseria spp. and the hemophore Has system in $S$. marcescens. In addition, the use of an inner membrane ABC transporter is a recurrent mechanism shared by many pathogenic bacteria for iron transport.

The lactoferrin uptake system LbpAB in the Neisseria species is very similar to TbpAB in that LbpA is a TonB-dependent outer membrane protein and $\mathrm{LbpB}$ is a lipoprotein that serves as a coreceptor for LbpA (Biswas and Sparling, 1995). In contrast to the situation with $\mathrm{TbpB}$ and transferrin, $\mathrm{LbpB}$ is not required for uptake of iron from lactoferrin (Biswas et al., 1999). The specific mechanism of iron extraction from lactoferrin remains to be elucidated. Lactoferrin receptors are only found in about $50 \%$ of clinical isolates, whereas all isolates of $N$. gonorrhoeae express receptors that bind human transferrin. However, in vivo experiments demonstrated that the expression of the lactoferrin receptor in the absence of the transferrin receptor is sufficient for establishment of infection. Furthermore, in a mixed infection of male volunteers, expression of both lactoferrin and transferrin receptors gave a competitive advantage over a strain expressing only the transferrin receptor, thereby further indicating a role in virulence for iron acquisition from lactoferrin (Anderson et al., 2003).

\section{INVOLVEMENT OF CATECHOLAMINES IN IRON ACOUISITION FROM TRANSFERRIN AND LACTOFERRIN}

The availability of iron from transferrin and lactoferrin for bacterial use is also influenced by catecholamine stress hormones (epinephrine, norepinephrine and dopamine) and inotropes (isoprenaline and dobutamine) (Freestone et al., 2000, 2002; Neal et al., 2001; O’Donnell et al., 2006). Catecholamine stress hormones are able to bind transferrin and lactoferrin, to form direct complexes with ferric iron, and to reduce ferric to ferrous iron with subsequent liberation from transferrin (Sandrini et al., 2010). Free iron can then be used for bacterial growth via other specific iron uptake systems. This ability of stress hormones to mediate bacterial iron acquisition from transferrin and lactoferrin has been proposed to function in biofilm formation in intravenous lines by the Gram-positive bacterium S. epidermidis (Lyte et al., 2003). It may also play a role in the development of intra-abdominal sepsis by E. coli (Freestone et al., 2002) and be a contributing factor in biofilm formation on endotracheal tubing during ventilator-associated pneumonia caused by $P$. aeruginosa (Freestone et al., 2012).

For bacterial pathogens, iron acquisition involving catecholamines is mediated by siderophores or by mechanisms that are partially or completely independent of siderophore function. For example, enterohemorrhagic E. coli O157:H7 and Salmonella enterica can grow on transferrin in the presence of norepinephrine. The growth of both species in the presence of transferrin and norepinephrine also requires the synthesis, transport, and degradation of the siderophore enterobactin, suggesting that once iron is release from transferrin by a catecholamine, it is transported inside the bacteria by enterobactin. (Freestone et al., 2003; Methner et al., 2008). The transport of iron by enterobactin is discussed in more detail below. Bordetella bronchiseptica also uses catecholamines (norepinephrine, epinephrine, and dopamine) to obtain iron from both transferrin and lactoferrin (Anderson and Armstrong, 2008; Armstrong et al., 2012). The efficiency of iron acquisition from transferrin in the presence of catecholamine is increased by addition of enterobactin, but the siderophore is not essential, since norepinephrine alone can stimulate growth in presence of transferrin. This growth stimulation is dependent on TonB because a mutation in $\operatorname{ton} B$ abolishes growth in presence of transferrin and NE (Anderson and Armstrong, 2008). A genetic screen identified three TonB-dependent outer membrane receptors ( $\mathrm{Bfr} \mathrm{A}, \mathrm{BfrD}$, and $\mathrm{BfrE}$ ) for catecholamines that are required for growth in the presence of catecholamines and transferrin. These receptors can also mediate the uptake of 
enterobactin and 2,3-dihydroxybenzoic acid. The characterization of catecholamine-mediated iron uptake for B. bronchiseptica revealed a siderophore-independent pathway. However, its features imply that siderophores may act to shuttle iron between transferrin and outer membrane receptors (Armstrong et al., 2012).

Growth stimulation by norepinephrine in the presence of transferrin has been also shown to be independent of siderophore production for E. coli and Bacillus subtilis (Miethke and Skerra, 2010). Mutants with defects in siderophore biosynthesis in both bacteria are still able to grow in the presence of norepinephrine and transferrin, indicating that iron-complexed norepinephrine can directly serve as an iron source. However, the FeuABC uptake system for bacillibactin was also identified in B. subtilis to be involved in the use of iron-complexed norepinephrine, since deletion of this locus abolished growth stimulation by NE and transferrin (Miethke et al., 2006). Furthermore, this iron acquisition could be abolished by the addition of siderocalin, the host innate immune protein that binds enterobactin and inhibits its use by the bacteria (Miethke and Skerra, 2010). A similar system may operate in other Gram-positive bacteria because a siderophoredeficient strain of $S$. aureus can grow in human serum in the presence of catecholamines (epinephrine, norepinephrine, and dopamine). In this case, iron uptake via catecholamine sequestration is mediated by the transporter SstABCD, as shown in Figure 3. Based on sequence similarities, the sst genes encode two putative cytoplasmic membrane proteins (SstA and SstB), an ATPase (SstC), and a membrane-bound lipoprotein (SstD) (Morrissey et al., 2000). Moreover, S. aureus can use its endogenous siderophores, staphyloferrin $\mathrm{A}$ and staphyloferrin $\mathrm{B}$, to access the transferrin iron pool (Beasley et al., 2011). The collective activities of the siderophore transporters (Hts and Sir) and the Sst transport system are required for full virulence of $S$. aureus in intravenously challenged mice. However, sst inactivation was sufficient to significantly decrease colonization of the mouse heart (Beasley et al., 2011).

\section{FUNGAL ACOUISITION OF IRON FROM TRANSFERRIN AND LACTOFERRIN}

Transferrin and lactoferrin are known to have an inhibitory effect on the growth of the pathogenic fungi A. fumigatus, C. albicans and C. neoformans (Sridhar et al., 2000; Ahluwalia et al., 2001; Lahoz et al., 2008; Almeida et al., 2009; Kornitzer, 2009; Okazaki et al., 2009). The mechanism of inhibition is probably due to iron sequestration by partially iron-loaded protein because additional studies have shown that these fungi can acquire iron from fully iron-loaded transferrin under specific conditions. For example, iron-loaded transferrin, but not apo-transferrin, restores growth to iron-starved cells of C. albicans (Knight et al., 2005). In this fungus, the use of transferrin iron is dependent on fungal contact with the transferrin and on a reductive, high affinity uptake system that includes the iron permease Ftr1 and a reductase Fre10 (Figure 3). Importantly, Ftr1 is required for virulence thus suggesting iron acquisition from transferrin during infection (Ramanan and Wang, 2000). Siderophore and heme uptake systems did not play a role in iron acquisition from transferrin by C. albicans. In contrast, A. fumigatus uses secreted siderophores to obtain iron from transferrin and this may be important during disease (Hissen et al., 2004; Hissen and Moore, 2005; Haas, 2012). The situation for $C$. neoformans resembles that of $C$. albicans where an iron permease, $\mathrm{Cft} 1$, of the reductive, high affinity system is required for iron use from transferrin and for full virulence (Jung et al., 2008).

\section{IRON ACQUISITION FROM FERRITINS}

Ferritins represent a potentially rich source of iron for bacteria and fungi. For example, N. meningitides is able to use iron from ferritin after a rapid redistribution and degradation of cytosolic ferritin in infected epithelial cells (Larson et al., 2004). Ferritin is in fact aggregated and recruited by intracellular meningococci and degradation of ferritin provides an excellent source of iron (Larson et al., 2004). For the fungi, ferritin use as a sole iron source has been best characterized for C. albicans. This pathogen uses the adhesin Als3 as a ferritin receptor, as demonstrated by the findings that deletion of als 3 blocks ferritin binding and that heterologous expression of Als3 in S. cerevisiae confers the ability to bind ferritin (Almeida et al., 2008).

\section{FERRIC IRON ACQUISITION BY SIDEROPHORES}

Many bacteria and fungi (and perhaps mammals) produce siderophores (low molecular weight, high affinity ferric chelators) to acquire and transport iron, as detailed in several reviews (Andrews et al., 2003; Miethke and Marahiel, 2007; Winkelmann, 2007; Haas et al., 2008). The first three siderophores were isolated and identified from bacteria (mycobactin and coprogen) and fungi (ferrichrome). Snow and collaborators first reported in 1949 that supplementation with purified mycobactin enhanced the growth of Mycobacterium johnei (also known as M. paratuberculosis) (Francis et al., 1949). Mycobactin was considered to be a growth factor, although a high affinity for ferric chloride was also noted (Francis et al., 1953; Snow, 1954). Early experiments identified other growth factors with apparently dissimilar structures but strong chelating activity for ferric iron, including the Terregens Factor (later identified as arthrobactin), coprogen, and ferrichrome (Hesseltine et al., 1952; Lochead et al., 1952; Neilands, 1957). Garibaldi and Neilands reported the key finding that the production of ferrichrome A was enhanced when the fungus Ustilago sphaerogena was grown in iron-depleted medium, and that several other microbes (e.g., the bacteria B. subtilis and Bacillus megaterium, and the fungus Aspergillus niger) produced iron-binding compounds under similar conditions (Garibaldi and Neilands, 1956). This work led to the suggestion that the growth factors might be involved in a system for sequestering and transferring iron that is induced during iron deficiency. This key observation led to a refined view of the function of siderophores and their biological significance. In fact, siderophores enhance growth by coordinating ferric iron for uptake by microorganisms using facilitative transport machinery.

Numerous reviews have appeared describing the types of siderophores produced by microbes (Crosa and Walsh, 2002; Winkelmann, 2002, 2007; Andrews et al., 2003; Miethke and Marahiel, 2007; Haas et al., 2008). Therefore, we will focus on selected principles and examples for bacterial and fungal pathogens to illustrate general properties. Importantly, in 
addition to a role in iron acquisition in the context of infection, some siderophores are secreted by microorganisms to deprive competing organisms of iron (Emery, 1982). Conversely, many microorganisms have evolved the transport machinery to use heterologous siderophores produced by other microbes (xenosiderophores) (Winkelmann, 2007). This is the case for opportunistic pathogen $P$. aeruginosa which produces two different siderophores, pyoverdine and pyochelin (Cox, 1980; Cox and Adams, 1985), but can utilize a variety of heterologous siderophores from other bacteria and fungi, including ferrioxamine B, ferrichrome and enterobactin (Poole et al., 1990; Cuiv et al., 2007). A focus on the use of xenosiderophores is also the case for the fungal pathogens $C$. albicans and $C$. neoformans, as described below. Of course, many pathogenic microorganisms produce siderophores that are directly implicated in their virulence (Miethke and Marahiel, 2007; Garenaux et al., 2011). In this case, siderophores of bacterial and fungal pathogens can directly remove iron from host proteins such as transferrin to support proliferation in vertebrates (Konopka et al., 1982; Brock et al., 1983).

\section{ENTEROBACTIN, THE ARCHETYPICAL SIDEROPHORE}

The archetypical bacterial siderophore is the catecholate enterobactin, also known as enterochelin. This siderophore was identified simultaneously by O'Brien and Gibson (1970), who isolated enterochelin from E. coli, and Pollack and Neilands (1970), who characterized enterobactin from $S$. enterica Typhimurium. Enterobactin has been extensively studied over the past 40 years and it is the siderophore with the strongest known affinity for ferric iron $\left(K_{\mathrm{d}}\right.$ of $\left.10^{-52} \mathrm{M}\right)$ (Harris et al., 1979). Enterobactin participates in the retrieval of iron from transferrin, as discussed earlier, and the siderophore is produced by E. coli, Salmonella spp., Klebsiella spp, and by some strains of Shigella (Wyckoff et al., 2009). Enterobactin can, however, be sequestered by the host innate immune protein siderocalin (also known as lipocalin 2) as a defense mechanism to prevent bacteria from accessing iron (Goetz et al., 2002; Flo et al., 2004). In response, the pathogenic enterobacteria don't rely solely on enterobactin to gain access to iron within the host and they possess multiple siderophore systems. In particular, enterobactin can be modified into salmochelins by the addition of up to three glucose molecules on its catechol moieties (Hantke et al., 2003; Bister et al., 2004). This glycosylation blocks binding by siderocalin without altering iron binding by the siderophore (Fischbach et al., 2006). Hence, the production of salmochelins contributes to virulence of pathogenic E. coli, S. Typhimurium, and K. pneumoniae (Caza et al., 2008, 2011; Crouch et al., 2008; Bachman et al., 2012). Two other types of siderophores can be produced by these bacteria, aerobactin and yersiniabactin, and these can also escape siderocalin sequestration and contribute to the virulence of pathogenic E. coli and K. pneumoniae (Dozois et al., 2003; Fischbach et al., 2006; Bachman et al., 2011; Correnti and Strong, 2012).

A common observation is that pathogens often deploy multiple iron acquisition systems or siderophores to support proliferation in the host (Dozois et al., 2003; Garenaux et al., 2011;
Kronstad et al., 2013). In particular, redundancy in siderophore iron acquisition systems can mask the contribution of each individual system to virulence. A good example comes from the production of pyochelin and pyoverdine by $P$. aeruginosa. In an intramuscular infection model with immuno-compromised mice, only the strain mutated for the production of both pyochelin and pyoverdine showed attenuation of virulence. However, in an intranasal murine model of infection, only pyoverdine is required for pathogenesis, although loss of both molecules more severely attenuated virulence (Takase et al., 2000).

\section{SIDEROPHORE TRANSPORT IN GRAM-NEGATIVE BACTERIA}

Typically, the internalization of siderophores in bacteria is facilitated by $\mathrm{ABC}$ type transporters. Although in some cases, inner membrane permeases driven by energy proton motrive force can also translocate iron-loaded siderophores. The iron-loaded siderophore is first recognized and internalized by specific cellsurface receptors, which are all members of the TBDT family and are usually regulated by Fur. The ferri-siderophore is then processed through the different membranes and the cell wall by chaperone proteins and facilitators. Once the molecule reaches the intracellular space, the iron atom can be released by physical degradation of the siderophore or by a redox-mediated process, the affinity of siderophores for ferrous iron being much less than that for ferric iron. In some cases, such as with pyoverdine uptake by $P$. aeruginosa, iron can be released in the periplasmic space with subsequent transport of siderophore-free iron into the cytoplasm and recycling of the empty siderophore to the extracellular medium (Faraldo-Gomez and Sansom, 2003; Wandersman and Delepelaire, 2004; Schalk and Guillon, 2013).

For Gram-negative bacteria, iron-loaded siderophores need to pass two membranes and a peptidoglycan cell wall to reach the intracellular space (Figure 4). Recognition and internalization requires specific receptors on the cell surface and examples include FepA, IroN, and PfeA from E. coli, S. enterica and $P$. aeruginosa, respectively (Lundrigan and Kadner, 1986; Dean and Poole, 1993; Hantke et al., 2003). A single transport system can also internalize different siderophores. For example, the internalization of the siderophore aerobactin in $E$. coli is supported by the receptor IutA and the $\mathrm{ABC}$ transporter FhuBCD (De Lorenzo et al., 1986; Wooldridge et al., 1992). This transporter also mediates the uptake of ferrichrome, coprogen and rhodotorulic acid with the help of the specific receptors FhuA, FhuE, and Fiu (Fecker and Braun, 1983; Hantke, 1983). This illustrates the versatility of receptor-substrate recognition and also the piracy for iron acquisition that exists among competitive pathogens. The detailed processes of siderophore internalization are illustrated in Figure 4 for the well-characterized mechanism of the fur-regulated catecholate siderophores system, enterobactin, and salmochelins. Iron-loaded catecholate siderophores are translocated upon recognition by the outer membrane receptor FepA (for enterobactin only) or IroN coupled to the energy transducing TonB-ExbD-ExbB complex (Pierce et al., 1983). After internalization, ferri-siderophore moves through the inner membrane. This passage requires proteins located in the periplasmic space and an inner membrane transporter. Cyclic molecules can be linearized in the periplasm by the esterase IroE (Lin et al., 2005; 


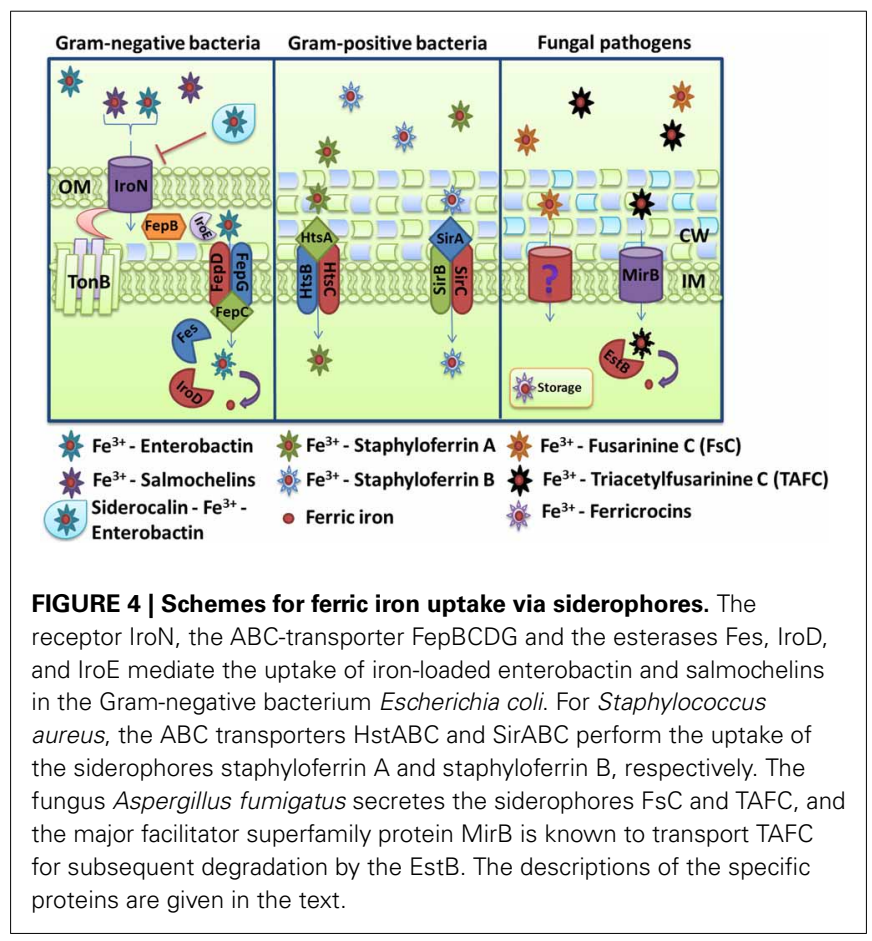

Zhu et al., 2005). The periplasmic protein FepB and the ABC transporter FepCEG translocate iron-loaded siderophores into the bacterial cytoplasm (Shea and McIntosh, 1991; Sprencel et al., 2000; Crouch et al., 2008). Once in the cytoplasm, the release of iron requires degradation of the molecule. The esterases Fes and IroD cleave iron-loaded enterobactin and salmochelins at ester bonds creating monomers, dimers, and trimers of DHBS and their glycosylated versions (Langman et al., 1972; Lin et al., 2005). These molecules can then be resecreted outside the bacteria, via their specific efflux pump EntS and IroC and reutilized as siderophores (Caza et al., 2011). This recycling characteristic of siderophore molecules is similar to the recycling of transferrin receptors and hemophores.

\section{SIDEROPHORE TRANSPORT IN GRAM-POSITIVE BACTERIA}

Siderophore transport in gram-positive bacteria is similar to the process in Gram-negative bacteria in that $\mathrm{ABC}$ transporters mediate translocation into the cytoplasm. The system in $S$. aureus provides a good illustration of the process. This bacterium produces for two siderophores, staphyloferrin A and staphyloferrin B, which are transported into the cytoplasm through the ABC transporters HtsABC and SirABC, respectively (Figure 4) (Meiwes et al., 1990; Beasley et al., 2009). HtsA and SirA are receptors exposed on cell surface while HtsBC and SirBC are components in the membrane responsible for the transport into the cell (Beasley et al., 2011). HtsBC also participates in the uptake of heme, suggesting a dual role for the HtsABC transporter (Skaar et al., 2004). The $s f a$ and $s b n$ loci encode the enzymes for staphyloferrin A and staphyloferrin B biosynthesis, respectively, and are regulated negatively by Fur and iron (Beasley et al., 2009, 2011). As discussed earlier, these siderophores are able to acquire iron from transferrin and lactoferrin with the help of catecholamine, although they are also able to mediate the uptake of ferric iron directly. In addition, $S$. aureus can utilize exogenous hydroxamate siderophores like aerobactin, ferrichrome, ferrioxamine B and coprogen through the Fhu (FhuCBG, FhuD1and FhuD2) uptake system (Sebulsky et al., 2000; Sebulsky and Heinrichs, 2001). FhuB and FhuG are membrane components and FhuC is the ATP-binding protein. FhuD1 and FhuD2 are lipoproteins thought to function as binding proteins for hydroxamate siderophores and staphylobactin (Sebulsky et al., 2003). Assays with a $\triangle f h u C B G$ mutant revealed a significant contribution to virulence in a murine kidney abscess model (Speziali et al., 2006).

Listeria monocytogenes provides a useful additional example because this facultative intracellular pathogen uses several iron uptake systems. It can acquire iron from host proteins such as transferrin, lactoferrin, ferritin, and hemoglobin, but it does not secrete any siderophores. Rather it can use several hydroxamate (ferrichrome, ferrichrome A and ferrioxamine B) and catecholate (enterobactin and corynebactin) siderophores from other organisms and it can use additional iron-binding compounds, including catecholamines (Simon et al., 1995; Jin et al., 2006). As in $S$. aureus, the $\mathrm{ABC}$ transporter FhuCDBG system in L. monocytogenes is responsible for uptake of the hydroxamate siderophore ferrichrome and the HupDGC transporter mediates the uptake of iron from hemoglobin (Jin et al., 2006).

\section{SIDEROPHORE PRODUCTION AND TRANSPORT IN PATHOGENIC FUNGI}

As a group, fungi produce a number of structurally different siderophores and, as mentioned, some of the earliest studies of siderophores involved ferrichrome and ferrichrome A (Burnham and Neilands, 1961; Zalkin et al., 1964). The ferrichrome siderophore family illustrates the potential for complexity because it consists of 20 structurally different hexapeptides where modifications can occur on a common ferrichrome backbone molecule. These modifications include the addition, for example, of a hydroxymethyl group, a methyl group, or a lateral side chain. These alterations can generate derivatives such as ferricrocin, ferrichrysin, asperchrome D1 and B1, ferrirubin, ferrirhodin, ferrichrome A and other molecules (Winkelmann, 2007). At the other end of the spectrum, there are also fungi that do not produce any known siderophores (as with L. monocytogenes discussed above), but readily make use of xenosiderophores through the deployment of specific transporters. In general, fungi use transporters of the major facilitator protein superfamily, rather than $\mathrm{ABC}$ transporters, for siderophore internalization (Haas et al., 2003, 2008).

The importance of siderophores in fungal virulence in humans is nicely illustrated by detailed studies with the airborne pathogen A. fumigatus (and parallel comparative studies with the related saprotrophic species Aspergillus nidulans) (Eisendle et al., 2003; Schrettl et al., 2004, 2007; Haas, 2012). A. fumigatus produces the siderophores fusarinine $\mathrm{C}(\mathrm{FsC}) /$ triacetylfusarinine $\mathrm{C}$ (TAFC) and ferricrocin, and much is known about the regulation, biosynthesis, uptake and role in virulence for these molecules (Hissen et al., 2004; Schrettl et al., 2004, 2007; Kragl et al., 2007; Wallner et al., 2009; Haas, 2012). FsC and TAFC are excreted in response to iron deprivation and they function in extracellular iron binding with subsequent uptake by siderophore iron transporters 
(SITs) (Figure 4). A. fumigatus is predicted to encode 10 SITs (Haas, 2012) and two from A. nidulans have been functionally characterized: MirA was found to transport enterobactin and MirB was shown to take up TAFC in both $A$. nidulans and $A$. fumigatus (Haas et al., 2003; Raymond-Bouchard et al., 2012). After internalization, the intracellular release of iron from TAFC is achieved by hydrolysis of the siderophore backbone by the esterase EstB (Kragl et al., 2007). Interestingly, A. fumigatus possesses ferricrocin intracellular siderophores, and their production is coordinated with the morphology of the fungus. That is, ferricrocin (FC) is produced during filamentous hyphal growth, while hydroxyferricrocin (HFC) is produced within the conidial spores that are the infectious particles (Schrettl et al., 2007; Wallner et al., 2009). The intracellular siderophores are believed to function in iron storage (Schrettl et al., 2007; Wallner et al., 2009). Both intracellular and extracellular siderophores contribute to the virulence of A. fumigatus because the deletion of key genes for production results in avirulence in a murine model of invasive pulmonary aspergillosis (Schrettl et al., 2007). A recent study demonstrated that topical treatment with the human tear lipocalin (TL, also known as $\operatorname{Lcn} 1$ ) or lactoferrin reduced $A$. fumigatus growth in the cornea of mice, suggesting that therapeutic inhibition of fungal iron acquisition can be used to treat infections (Leal et al., 2013). TL is a secretory protein that interferes with microbial growth by scavenging microbial siderophores. In contrast to siderocalin, TL binds to a broader array of siderophores, including fungal siderophores such as coprogen, TAFC and rhodotorulic acid (Fluckinger et al., 2004).

The pathogenic yeasts $C$. albicans and $C$. neoformans don't produce siderophores but can scavenge xenosiderophores from other microbes. This iron parasitism depends on specific siderophore transporters in the plasma membrane. For example, the transporter Sit1 (also designated Sit1p/Arn1p) from $C$. albicans mediates the uptake of ferrichrome-type siderophores including ferricrocin, ferrichrysin, ferrirubin, coprogen and TAFC (Heymann et al., 2002). A mutant lacking Sit1 had a reduced ability to damage cells in a reconstituted human epithelium model of infection (Heymann et al., 2002). In C. neoformans, the transporter Sit1 is required for the uptake of ferrioxamine B, but does not make a contribution to virulence in a mouse model of cryptococcosis (Tangen et al., 2007).

\section{UPTAKE OF FERROUS IRON}

Activities for the reduction of ferric iron and subsequent uptake of ferrous iron are present in bacteria and fungi. The ferrous form can exist in acidic environments and under anoxic conditions, and it can be generated by cell-associated or exported reductase activities. Ferrous iron ions are believed to diffuse freely through the outer membrane of Gram-negative bacteria, with subsequent transport through the inner membrane by the $\mathrm{ABC}$ transporter FeoABC. This system is conserved in many species, and it was first discovered in the non-pathogenic E. coli strain K-12 (Kammler et al., 1993). FeoB is the main transmembrane transporter that acts as a permease, while FeoC has been proposed to regulate FeoB. The role of FeoA is not well-understood, but it interacts with the highly conserved core region of FeoB (Lau et al., 2013). This system is under control of fnr and fur regulatory elements, where Fnr is an anaerobically-induced transcriptional activator and Fur inhibits transcription of feo genes in iron-replete conditions (Spiro and Guest, 1990; Kammler et al., 1993). The Feo system also contributes to intracellular replication for facultative intracellular pathogens like Legionella pneumophila (Robey and Cianciotto, 2002), Shigella flexneri (Runyen-Janecky et al., 2003) and Francisella tularensis (Thomas-Charles et al., 2013).

Other ferrous iron transport systems are present in various bacterial species. For example, the SitABCD system exists in $S$. enterica and $E$. coli, and a similar system has been described in Y. pestis (YfeABCD) (Bearden and Perry, 1999). The Yfe system is a typical $\mathrm{ABC}$ transporter for ferrous iron and manganese. $\mathrm{YfeA}$ is a periplasmic binding protein, $\mathrm{YfeC}$ and $\mathrm{YfeD}$ are the two inner membrane permeases, and YfeB is the ATPase required for energy transduction transport. No outer membrane protein has been identified and transport is independent of TonB (Figure 5) (Bearden et al., 1998; Perry et al., 2003; Fetherston et al., 2010). The Fur-regulated EfeUOB system is found in enterohaemorrhagic E. coli O157:H7 and E. coli Nissle 1917, and is also thought to transport ferrous iron (Grosse et al., 2006; Cao et al., 2007). This system promotes growth under aerobic, low-pH and lowiron conditions in response to ferrous iron (Cao et al., 2007). Interestingly, the EfeUOB system is analogous to the reductive, high-affinity iron uptake system of S. cerevisiae (Ftr1-Fet3-Fre1). Frt1 is an iron permease (with homology to EfeU), Fet3 is a multicopper oxidase (MCO) that will oxidize ferrous iron to its ferric state during the translocation and Frel is one of seven reductases that reduce ferric iron (Kosman, 2003). The EfeUOB system also exists in the Gram-positive bacterium B. subtilis where it permits acquisition of both ferrous and ferric iron species depending on extracellular conditions (Miethke et al., 2013). The ferrous iron peroxidase EfeB and the ferric iron binding protein $\mathrm{EfeO}$ act in succession during ferrous oxidation and ferric iron delivery to the membrane permease EfeU. However, EfeB is dispensable for direct ferric uptake via EfeUO, but instead promotes growth under microaerobic conditions where ferrous iron is more abundant. EfeUOB thus has a dual mechanism for acquisition of iron (Figure 5) (Miethke et al., 2013). More recently, the FtrABCD system for ferrous iron transport has been characterized in Bordetella pertussis and Bordetella bronchiseptica, and in Brucella abortus (Brickman and Armstrong, 2012; Elhassanny et al., 2013). Importantly, a B. abortus mutant lacking FtrA is attenuated in murine macrophages and mice thereby indicating the importance of ferrous iron in the mammalian host.

As mentioned above for the yeast $S$. cerevisiae, fungi have a high affinity system consisting of reductases, an iron permease and a MCO to generate ferrous iron for uptake, and this is the case for A. fumigatus, C. albicans, and C. neoformans. The components of this system and its contribution to iron acquisition in a vertebrate host were first characterized for C. albicans. Two C. albicans reductases, Cfll and Cfl95, were identified that promote reduction of ferric iron upon heterologous expression in a $S$. cerevisiae reductase-deficient strain. A large number of additional reductases are predicted from the $C$. albicans genome sequence (Hammacott et al., 2000; Knight et al., 2002). As in S. cerevisiae, reduced iron is transported into the cell by a complex consisting of an MCO and a permease. Five MCO candidates are predicted 


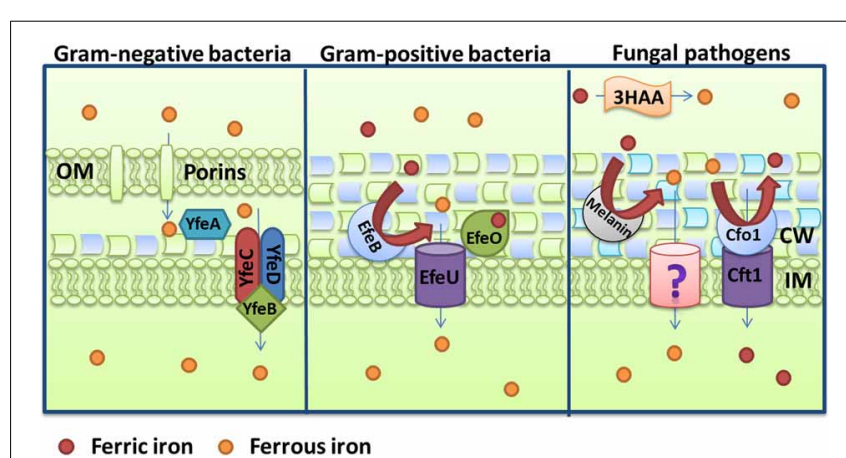

FIGURE 5 | Schemes for ferrous iron uptake. The Gram-negative bacterium Yersinia pestis uses the YfeABCD proteins and the Gram-positive bacterium Bacillus subtilis uses the EfeUOB complex to accomplish ferrous iron uptake. A comparable process is shown for the fungal pathogen Cryptococcus neoformans. This pathogen used the Cfo1-Cft1 multicopper oxidase-iron permease complex, the cell wall pigment melanin, and the secreted reductant 3-hydroxyanthranilic acid to perform reduction and ferrous iron uptake. Note that ferrous iron is oxidized by Cfo1 prior to transport into the cell by $\mathrm{Cft} 1$. Physiological evidence for an additional low affinity transport system for ferrous iron has been presented for $C$. neoformans and this is indicated by a question mark (Jacobson et al., 1998). Additional details for each system are provided in the text.

for C. albicans, and CaFET3, CaFET31 and CaFET43, can rescue the growth of a fet3 $\Delta$ (MCO) mutant of $S$. cerevisiae in response to iron limited conditions (Ziegler et al., 2011; Cheng et al., 2013). Moreover, deletion of CaFET33 and CaFET34 decreased cellular iron content and iron acquisition during iron starvation, and CaFET3 can compensate for the loss of CaFET33 and CaFET34 (Cheng et al., 2013). C. albicans has two iron permeases, CaFTR1 and CaFTR2. The expression of CaFRT1 is induced by iron starvation and this gene is required for iron acquisition from ferritin and transferrin (Ramanan and Wang, 2000; Almeida et al., 2009). A mutant that lacks the gene cannot cause damage to oral epithelial cells and, as mentioned earlier, is unable to cause systemic disease in a mouse model of candidiasis (Ramanan and Wang, 2000).

A screen of the A. fumigatus genome revealed 15 putative reductases, and FreB was shown to participate in adaptation to iron starvation and to function as a reductase (Blatzer et al., 2011). In this pathogen, the reduced ferrous iron is then reoxidized by the MCO FetC and imported by the iron permease FtrA; FetC and FtrA are 52\% and 55\% identical to the C. albicans Fet3 and Frt1 proteins, respectively (Schrettl et al., 2004). However, in A. fumigatus, the reductive iron uptake system does not play a role in virulence, and the siderophore system appears to be much more important for proliferation in the host (Schrettl et al., 2007; Haas, 2012).

The situation in C. neoformans is similar to that of C. albicans. Reductase activities have been characterized and the MCO $\mathrm{Cfo} 1$ as well as the iron permease $\mathrm{Cft} 1$ are required for reduction of iron from transferrin (Jung et al., 2009). Interestingly, in addition to enzymatic reductase activity, two other reduction systems exist at the cell surface for C. neoformans, the secreted reductant 3-hydrozyanthranilic acid (3HAA) and melanin which is responsible for a black cell wall pigmentation in presence of LDOPA (Figure 5) (Nyhus et al., 1997). Cfol and Cft1 are both required for full virulence of $C$. neoformans in an inhalation murine model of cryptococcosis, however, mutants lacking these enzymes still cause disease (Jung et al., 2008, 2009). Therefore, additional iron acquisition functions are needed during disease. One of these functions includes the mannoprotein Cig1 that was recently shown to participate in heme uptake, as described earlier (Cadieux et al., 2013).

\section{CONCLUSIONS AND PERSPECTIVES}

Pathogenic bacteria and fungi have evolved a number of mechanisms to acquire iron from different sources in the mammalian host. Although many of these mechanisms share functional similarities, it is clear that far more is known about bacterial systems. This is particularly evident for mechanisms that mediate iron acquisition from heme and heme-containing proteins. Considered as a group, key components have been identified in several bacterial pathogens and these include hemolysins, hemophores, receptors, $\mathrm{ABC}$ transporters for internalization and heme oxygenase activities. In contrast, the components that perform analogous functions in fungal pathogens are just now being identified and characterized. While there is some information about hemolysins and receptors, a candidate hemophore has only recently been described in a fungal pathogen and the details of uptake via endocytosis require considerable more investigation.

For other iron-containing host proteins, such as transferrin, lactoferrin and ferritin, there are clear differences between bacterial and fungal pathogens, although again the lack of information for fungi precludes detailed comparisons. It is clear that some bacteria, particularly Neisseria species, have sophisticated mechanisms for using transferrin, lactoferrin, and ferritin iron. In addition, there is a fascinating body of information on the participation of catecholamines in bacterial iron acquisition. This aspect of iron acquisition remains to be explored in fungal pathogens. For fungi, transferrin and lactoferrin tend to inhibit growth by an iron sequestration mechanism, although some fungi can overcome this limitation by reductive iron uptake or siderophore elaboration. Reductive iron uptake systems show similarities between bacteria and fungi in the uptake of ferrous iron, and this mechanism is clearly important for virulence in some but not all fungi. In addition, the recent discovery of a ferritin receptor in C. albicans has generated considerable interest in fungal exploitation of this iron source.

Siderophore-mediated acquisition of iron is one area where fungi as a group (i.e., not just pathogens) have provided significant structural and mechanistic information in parallel with studies in bacterial pathogens. In particular, the detailed studies in A. fumigatus (and the related species A. nidulans) on siderophore biosynthesis rival the sophisticated and advanced state of analysis for bacteria. However, the critical area of siderophore transport needs considerable attention for fungal pathogens. This is because little information is available for any of the species and because some of the most important species, C. albicans and C. neoformans, rely on transporters to steal siderophores. Considerable attention is now directed at siderophore-based drug development where siderophore transporters might be exploited as Trojan 
horse delivery systems. Therefore, an understanding of fungal siderophore transporters might facilitate the application of these drugs to fungal diseases. It is evident, however, that pathogenic bacteria and fungi generally possess more than one mechanism for exploiting the potential iron sources in vertebrate hosts. This is clear from virulence studies that often reveal only partial attenuation upon loss of a single uptake mechanism. Therefore, therapeutic approaches that target iron acquisition must inactivate the most critical of these mechanisms and/or exploit them for the delivery of antibacterial and antifungal drugs.

\section{ACKNOWLEDGMENTS}

Our research is supported by the Canadian Institutes of Health Research, the Natural Sciences and Engineering Research Council of Canada and the National Institute of Allergy and Infectious Diseases (RO1 AI053721). James W. Kronstad is a Burroughs Wellcome Fund Scholar Award in Molecular Pathogenic Mycology. We apologize to those authors whose work could not be cited due to space limitations.

\section{REFERENCES}

Adhikari, P., Berish, S. A., Nowalk, A. J., Veraldi, K. L., Morse, S. A., and Mietzner, T. A. (1996). The fbpABC locus of Neisseria gonorrhoeae functions in the periplasm-to-cytosol transport of iron. J. Bacteriol. 178, 2145-2149.

Ahluwalia, M., Brummer, E., Sridhar, S., Singh, R., and Stevens, D. A. (2001). Isolation and characterisation of an anticryptococcal protein in human cerebrospinal fluid. J. Med. Microbiol. 50, 83-89.

Aisen, P. (2004). Transferrin receptor 1. Int. J. Biochem. Cell. Biol. 36, 2137-2143. doi: 10.1016/j.biocel.2004.02.007

Aisen, P., and Brown, E. B. (1977). The iron-binding function of transferrin in iron metabolism. Semin. Hematol. 14, 31-53.

Aisen, P., Enns, C., and Wessling-Resnick, M. (2001). Chemistry and biology of eukaryotic iron metabolism. Int. J. Biochem. Cell. Biol. 33, 940-959. doi: 10.1016/S1357-2725(01)00063-2

Allen, C. E., Burgos, J. M., and Schmitt, M. P. (2013). Analysis of novel ironregulated, surface-anchored hemin-binding proteins in Corynebacterium diphtheriae. J. Bacteriol. 195, 2852-2863. doi: 10.1128/JB.00244-13

Allen, C. E., and Schmitt, M. P. (2009). HtaA is an iron-regulated hemin binding protein involved in the utilization of heme iron in Corynebacterium diphtheriae. J. Bacteriol. 191, 2638-2648. doi: 10.1128/JB.01784-08

Allen, C. E., and Schmitt, M. P. (2011). Novel hemin binding domains in the Corynebacterium diphtheriae HtaA protein interact with hemoglobin and are critical for heme iron utilization by HtaA. J. Bacteriol. 193, 5374-5385. doi: 10.1128/JB.05508-11

Almeida, R. S., Brunke, S., Albrecht, A., Thewes, S., Laue, M., Edwards, J. E., et al. (2008). the hyphal-associated adhesin and invasin Als3 of Candida albicans mediates iron acquisition from host ferritin. PLoS Pathog. 4:e1000217. doi: 10.1371/journal.ppat.1000217

Almeida, R. S., Wilson, D., and Hube, B. (2009). Candida albicans iron acquisition within the host. FEMS Yeast Res. 9, 1000-1012. doi: 10.1111/j.15671364.2009.00570.x

Anderson, G. J., Frazer, D. M., Wilkins, S. J., Becker, E. M., Millard, K. N., Murphy, T. L., et al. (2002). Relationship between intestinal iron-transporter expression, hepatic hepcidin levels and the control of iron absorption. Biochem. Soc. Trans. 30, 724-726. doi: 10.1042/BST0300724

Anderson, J. E., Hobbs, M. M., Biswas, G. D., and Sparling, P. F. (2003). Opposing selective forces for expression of the gonococcal lactoferrin receptor. Mol. Microbiol. 48, 1325-1337. doi: 10.1046/j.1365-2958.2003.03496.x

Anderson, J. E., Sparling, P. F., and Cornelissen, C. N. (1994). Gonococcal transferrin-binding protein 2 facilitates but is not essential for transferrin utilization. J. Bacteriol. 176, 3162-3170.

Anderson, M. T., and Armstrong, S. K. (2008). Norepinephrine mediates acquisition of transferrin-iron in Bordetella bronchiseptica. J. Bacteriol. 190, 3940-3947. doi: 10.1128/JB.00086-08
Andrade, M. A., Ciccarelli, F. D., Perez-Iratxeta, C., and Bork, P. (2002). NEAT: a domain duplicated in genes near the components of a putative $\mathrm{Fe} 3+$ siderophore transporter from Gram-positive pathogenic bacteria. Genome Biol. 3, RESEARCH0047. doi: 10.1186/gb-2002-3-9-research0047

Andrews, N. C. (2000). Iron homeostasis: insights from genetics and animal models. Nat. Rev. Genet. 1, 208-217. doi: 10.1038/35042073

Andrews, S. C., Robinson, A. K., and Rodriguez-Quinones, F. (2003). Bacterial iron homeostasis. FEMS Microbiol. Rev. 27, 215-237. doi: 10.1016/S01686445(03)00055-X

Anzaldi, L. L., and Skaar, E. P. (2010). Overcoming the heme paradox: heme toxicity and tolerance in bacterial pathogens. Infect. Immun. 78, 4977-4989. doi: 10.1128/IAI.00613-10

Armstrong, S. K., Brickman, T. J., and Suhadolc, R. J. (2012). Involvement of multiple distinct Bordetella receptor proteins in the utilization of iron liberated from transferrin by host catecholamine stress hormones. Mol. Microbiol. 84, 446-462. doi: $10.1111 / j .1365-2958.2012 .08032 . x$

Arnoux, P., Haser, R., Izadi-Pruneyre, N., Lecroisey, A., and Czzzek, M. (2000). Functional aspects of the heme bound hemophore HasA by structural analysis of various crystal forms. Proteins 41, 202-210. doi: 10.1002/10970134(20001101)41:2<202::AID-PROT50>3.0.co;2-8

Asano, T., Komatsu, M., Yamaguchi-Iwai, Y., Ishikawa, F., Mizushima, N., and Iwai, K. (2011). Distinct mechanisms of ferritin delivery to lysosomes in iron-depleted and iron-replete cells. Mol. Cell Biol. 31, 2040-2052. doi: 10.1128/MCB.01437-10

Ascenzi, P., Bocedi, A., Visca, P., Altruda, F., Tolosano, E., Beringhelli, T., et al. (2005). Hemoglobin and heme scavenging. IUBMB Life 57, 749-759. doi: 10.1080/15216540500380871

Bachman, M. A., Lenio, S., Schmidt, L., Oyler, J. E., and Weiser, J. N. (2012). Interaction of lipocalin 2, transferrin, and siderophores determines the replicative niche of Klebsiella pneumoniae during pneumonia. mBio 3:e0224-11. doi: 10.1128/mBio.00224-11

Bachman, M. A., Oyler, J. E., Burns, S. H., Caza, M., Lepine, F., Dozois, C. M., et al. (2011). Klebsiella pneumoniae yersiniabactin promotes respiratory tract infection through evasion of lipocalin 2. Infect. Immun. 79, 3309-3316. doi: 10.1128/IAI.05114-11

Bagg, A., and Neilands, J. B. (1987). Molecular mechanism of regulation of siderophore-mediated iron assimilation. Microbiol. Rev. 51, 509-518.

Baker, H. M., and Baker, E. N. (2004). Lactoferrin and iron: structural and dynamic aspects of binding and release. Biometals 17, 209-216. doi: 10.1023/B:BIOM.0000027694.40260.70

Balderas, M. A., Nobles, C. L., Honsa, E. S., Alicki, E. R., and Maresso, A. W. (2012). Hal is a Bacillus anthracis heme acquisition protein. J. Bacteriol. 194, 5513-5521. doi: 10.1128/JB.00685-12

Barker, K. D., Barkovits, K., and Wilks, A. (2012). Metabolic flux of extracellular heme uptake in Pseudomonas aeruginosa is driven by the ironregulated heme oxygenase (HemO). J. Biol. Chem. 287, 18342-18350. doi: 10.1074/jbc.M112.359265

Bates, C. S., Montanez, G. E., Woods, C. R., Vincent, R. M., and Eichenbaum, Z. (2003). Identification and characterization of a Streptococcus pyogenes operon involved in binding of hemoproteins and acquisition of iron. Infect. Immun. 71, 1042-1055. doi: 10.1128/IAI.71.3.1042-1055.2003

Bearden, S. W., and Perry, R. D. (1999). The Yfe system of Yersinia pestis transports iron and manganese and is required for full virulence of plague. Mol. Microbiol. 32, 403-414. doi: 10.1046/j.1365-2958.1999.01360.x

Bearden, S. W., Staggs, T. M., and Perry, R. D. (1998). An ABC transporter system of Yersinia pestis allows utilization of chelated iron by Escherichia coli SAB11. J. Bacteriol. 180, 1135-1147.

Beasley, F. C., Marolda, C. L., Cheung, J., Buac, S., and Heinrichs, D. E. (2011). Staphylococcus aureus transporters Hts, Sir, and Sst capture iron liberated from human transferrin by Staphyloferrin A, Staphyloferrin B, and catecholamine stress hormones, respectively, and contribute to virulence. Infect. Immun. 79, 2345-2355. doi: 10.1128/IAI.00117-11

Beasley, F. C., Vines, E. D., Grigg, J. C., Zheng, Q., Liu, S., Lajoie, G. A., et al. (2009). Characterization of staphyloferrin A biosynthetic and transport mutants in Staphylococcus aureus. Mol. Microbiol. 72, 947-963. doi: 10.1111/j.1365-2958.2009.06698.x

Benevides-Matos, N., Wandersman, C., and Biville, F. (2008). HasB, the Serratia marcescens TonB paralog, is specific to HasR. J. Bacteriol. 190, 21-27. doi: 10.1128/JB.01389-07 
Bhakta, M. N., and Wilks, A. (2006). The mechanism of heme transfer from the cytoplasmic heme binding protein PhuS to the delta-regioselective heme oxygenase of Pseudomonas aeruginosa. Biochemistry 45, 11642-11649. doi: 10.1021/bi0609801

Bister, B., Bischoff, D., Nicholson, G. J., Valdebenito, M., Schneider, K., Winkelmann, G., et al. (2004). The structure of salmochelins: Cglucosylated enterobactins of Salmonella enterica. Biometals 17, 471-481. doi: 10.1023/B:BIOM.0000029432.69418.6a

Biswas, G. D., Anderson, J. E., Chen, C. J., Cornelissen, C. N., and Sparling, P. F. (1999). Identification and functional characterization of the Neisseria gonorrhoeae lbpB gene product. Infect. Immun. 67, 455-459.

Biswas, G. D., and Sparling, P. F. (1995). Characterization of lbpA, the structural gene for a lactoferrin receptor in Neisseria gonorrhoeae. Infect. Immun. 63, 2958-2967.

Blatzer, M., Binder, U., and Haas, H. (2011). The metalloreductase FreB is involved in adaptation of Aspergillus fumigatus to iron starvation. Fungal Genet. Biol. 48, 1027-1033. doi: 10.1016/j.fgb.2011.07.009

Bleackley, M. R., Wong, A. Y., Hudson, D. M., Wu, C. H., and Macgillivray, R. T. (2009). Blood iron homeostasis: newly discovered proteins and iron imbalance. Transfus. Med. Rev. 23, 103-123. doi: 10.1016/j.tmrv.2008.12.001

Boulton, I. C., Gorringe, A. R., Allison, N., Robinson, A., Gorinsky, B., Joannou, C. L., et al. (1998). Transferrin-binding protein B isolated from Neisseria meningitidis discriminates between apo and diferric human transferrin. Biochem. J. 334(Pt 1), 269-273.

Bracken, C. S., Baer, M. T., Abdur-Rashid, A., Helms, W., and Stojilikovic, I. (1999). Use of heme-protein complexes by the Yersinia enterocolitica HemR receptor: histidine residues are essential for receptor function. J. Bacteriol. 181, 6063-6072.

Braun, V., and Braun, M. (2002). Active transport of iron and siderophore antibiotics. Curr. Opin. Microbiol. 5, 194-201. doi: 10.1016/S1369-5274(02)00298-9

Brickman, T. J., and Armstrong, S. K. (2012). Iron and pH-responsive FtrABCD ferrous iron utilization system of Bordetella species. Mol. Microbiol. 86, 580-593. doi: $10.1111 / \mathrm{mmi} .12003$

Brock, J. H., Pickering, M. G., McDowall, M. C., and Deacon, A. G. (1983). Role of antibody and enterobactin in controlling growth of Escherichia coli in human milk and acquisition of lactoferrin- and transferrin-bound iron by Escherichia coli. Infect. Immun. 40, 453-459.

Bullen, J. J., Leigh, L. C., and Rogers, H. J. (1968). The effect of iron compounds on the virulence of Escherichia coli for guinea-pigs. Immunology 15, 581-588.

Burnham, B. F., and Neilands, J. B. (1961). Studies on the metabolic function of the ferrichrome compounds. J. Biol. Chem. 236, 554-559.

Cadieux, B., Lian, T., Hu, G., Wang, J., Biondo, C., Teti, G., et al. (2013). The Mannoprotein Cig1 supports iron acquisition from heme and virulence in the pathogenic fungus Cryptococcus neoformans. J Infect Dis 207, 1339-1347. doi: 10.1093/infdis/jit029

Cao, J., Woodhall, M. R., Alvarez, J., Cartron, M. L., and Andrews, S. C. (2007) EfeUOB (YcdNOB) is a tripartite, acid-induced and CpxAR-regulated, low$\mathrm{pH} \mathrm{Fe} 2+$ transporter that is cryptic in Escherichia coli $\mathrm{K}-12$ but functional in E. coli O157:H7. Mol. Microbiol. 65, 857-875. doi: 10.1111/j.1365-2958.2007. 05802.x

Caza, M., Lepine, F., and Dozois, C. M. (2011). Secretion, but not overall synthesis, of catecholate siderophores contributes to virulence of extraintestinal pathogenic Escherichia coli. Mol. Microbiol. 80, 266-282. doi: 10.1111/j.13652958.2011.07570.x

Caza, M., Lepine, F., Milot, S., and Dozois, C. M. (2008). Specific roles of the iroBCDEN genes in virulence of an avian pathogenic Escherichia coli O78 strain and in production of salmochelins. Infect. Immun. 76, 3539-3549. doi: 10.1128/IAI.00455-08

Chen, C., Pande, K., French, S. D., Tuch, B. B., and Noble, S. M. (2011). An iron homeostasis regulatory circuit with reciprocal roles in Candida albicans commensalism and pathogenesis. Cell Host Microbe 10, 118-135. doi: 10.1016/j.chom.2011.07.005

Cheng, X., Xu, N., Yu, Q., Ding, X., Qian, K., Zhao, Q., et al. (2013). Novel insight into the expression and function of the multicopper oxidases in Candida albicans. Microbiology 159, 1044-1055. doi: 10.1099/mic.0.065268-0

Cope, L. D., Love, R. P., Guinn, S. E., Gilep, A., Usanov, S., Estabrook, R. W., et al. (2001). Involvement of HxuC outer membrane protein in utilization of hemoglobin by Haemophilus influenzae. Infect. Immun. 69, 2353-2363. doi: 10.1128/IAI.69.4.2353-2363.2001
Cope, L. D., Yogev, R., Muller-Eberhard, U., and Hansen, E. J. (1995). A gene cluster involved in the utilization of both free heme and heme:hemopexin by Haemophilus influenzae type b. J. Bacteriol. 177, 2644-2653.

Cornelis, P., Wei, Q., Andrews, S. C., and Vinckx, T. (2011). Iron homeostasis and management of oxidative stress response in bacteria. Metallomics 3, 540-549. doi: 10.1039/clmt00022e

Cornelissen, C. N., Biswas, G. D., Tsai, J., Paruchuri, D. K., Thompson, S. A., and Sparling, P. F. (1992). Gonococcal transferrin-binding protein 1 is required for transferrin utilization and is homologous to TonB-dependent outer membrane receptors. J. Bacteriol. 174, 5788-5797.

Cornelissen, C. N., Kelley, M., Hobbs, M. M., Anderson, J. E., Cannon, J. G., Cohen, M. S., et al. (1998). The transferrin receptor expressed by gonococcal strain FA1090 is required for the experimental infection of human male volunteers. Mol. Microbiol. 27, 611-616. doi: 10.1046/j.1365-2958.1998.00710.x

Cornelissen, C. N., and Sparling, P. F. (1996). Binding and surface exposure characteristics of the gonococcal transferrin receptor are dependent on both transferrin-binding proteins. J. Bacteriol. 178 1437-1444.

Correnti, C., Richardson, V., Sia, A. K., Bandaranayake, A. D., Ruiz, M., Suryo Rahmanto, Y., et al. (2012). Siderocalin/Lcn2/NGAL/24p3 does not drive apoptosis through gentisic acid mediated iron withdrawal in hematopoietic cell lines. PLoS ONE 7:e43696. doi: 10.1371/journal.pone.0043696

Correnti, C., and Strong, R. K. (2012). Mammalian siderophores, siderophorebinding lipocalins, and the labile iron pool. J. Biol. Chem. 287, 13524-13531. doi: 10.1074/jbc.R111.311829

Cox, C. D. (1980). Iron uptake with ferripyochelin and ferric citrate by Pseudomonas aeruginosa. J. Bacteriol. 142, 581-587.

Cox, C. D., and Adams, P. (1985). Siderophore activity of pyoverdin for Pseudomonas aeruginosa. Infect. Immun. 48, 130-138.

Crosa, J. H., and Walsh, C. T. (2002). Genetics and assembly line enzymology of siderophore biosynthesis in bacteria. Microbiol. Mol. Biol. Rev. 66, 223-249. doi: 10.1128/MMBR.66.2.223-249.2002

Crouch, M. L., Castor, M., Karlinsey, J. E., Kalhorn, T., and Fang, F. C. (2008). Biosynthesis and IroC-dependent export of the siderophore salmochelin are essential for virulence of Salmonella enterica serovar Typhimurium. Mol. Microbiol. 67, 971-983. doi: 10.1111/j.1365-2958.2007.06089.x

Cuiv, P. O., Keogh, D., Clarke, P., and O'connell, M. (2007). FoxB of Pseudomonas aeruginosa functions in the utilization of the xenosiderophores ferrichrome, ferrioxamine $\mathrm{B}$, and schizokinen: evidence for transport redundancy at the inner membrane. J. Bacteriol. 189, 284-287. doi: 10.1128/JB.01142-06

Curzon, G., and O'reilly, S. (1960). A coupled iron-caeruloplasmin oxidation system. Biochem. Biophys. Res. Commun. 2, 284-286. doi: 10.1016/0006291X(60)90185-6

Cwerman, H., Wandersman, C., and Biville, F. (2006). Heme and a fiveamino-acid hemophore region form the bipartite stimulus triggering the has signaling cascade. J. Bacteriol. 188, 3357-3364. doi: 10.1128/JB.188.9.33573364.2006

Daou, N., Buisson, C., Gohar, M., Vidic, J., Bierne, H., Kallassy, M., et al. (2009). IlsA, a unique surface protein of Bacillus cereus required for iron acquisition from heme, hemoglobin and ferritin. PLoS Pathog. 5:e1000675. doi: 10.1371/journal.ppat.1000675

Dautry-Varsat, A., Ciechanover, A., and Lodish, H. F. (1983). pH and the recycling of transferrin during receptor-mediated endocytosis. Proc. Natl. Acad. Sci. U.S.A. 80, 2258-2262. doi: 10.1073/pnas.80.8.2258

De Domenico, I., Vaughn, M. B., Li, L., Bagley, D., Musci, G., Ward, D. M., et al. (2006). Ferroportin-mediated mobilization of ferritin iron precedes ferritin degradation by the proteasome. EMBO J. 25, 5396-5404. doi: 10.1038/sj.emboj.7601409

De Lorenzo, V., Bindereif, A., Paw, B. H., and Neilands, J. B. (1986). Aerobactin biosynthesis and transport genes of plasmid ColV-K30 in Escherichia coli K-12. J. Bacteriol. 165, 570-578.

De Lorenzo, V., Wee, S., Herrero, M., and Neilands, J. B. (1987). Operator sequences of the aerobactin operon of plasmid ColV-K30 binding the ferric uptake regulation (fur) repressor. J. Bacteriol. 169, 2624-2630.

Dean, C. R., and Poole, K. (1993). Cloning and characterization of the ferric enterobactin receptor gene (pfeA) of Pseudomonas aeruginosa. J. Bacteriol. 175, 317-324.

Delaby, C., Rondeau, C., Pouzet, C., Willemetz, A., Pilard, N., Desjardins, M., et al. (2012). Subcellular localization of iron and heme metabolism related proteins 
at early stages of erythrophagocytosis. PLoS ONE 7:e42199. doi: 10.1371/journal.pone.0042199

Deriu, E., Liu, J. Z., Pezeshki, M., Edwards, R. A., Ochoa, R. J., Contreras, H., et al. (2013). Probiotic bacteria reduce salmonella typhimurium intestinal colonization by competing for iron. Cell Host Microbe 14, 26-37. doi: 10.1016/j.chom.2013.06.007

Derocco, A. J., Yost-Daljev, M. K., Kenney, C. D., and Cornelissen, C. N. (2009). Kinetic analysis of ligand interaction with the gonococcal transferrin-iron acquisition system. Biometals 22, 439-451. doi: 10.1007/s10534-008-9179-y

Devireddy, L. R., Gazin, C., Zhu, X., and Green, M. R. (2005). A cell-surface receptor for lipocalin $24 \mathrm{p} 3$ selectively mediates apoptosis and iron uptake. Cell 123, 1293-1305. doi: 10.1016/j.cell.2005.10.027

Devireddy, L. R., Hart, D. O., Goetz, D. H., and Green, M. R. (2010). A mammalian siderophore synthesized by an enzyme with a bacterial homolog involved in enterobactin production. Cell 141, 1006-1017. doi: 10.1016/j.cell.2010.04.040

Dlouhy, A. C., and Outten, C. E. (2013). The iron metallome in eukaryotic organisms. Met. Ions Life Sci. 12, 241-278. doi: 10.1007/978-94-0075561-1_8

Donovan, A., Brownlie, A., Zhou, Y., Shepard, J., Pratt, S. J., Moynihan, J., et al. (2000). Positional cloning of zebrafish ferroportinl identifies a conserved vertebrate iron exporter. Nature 403, 776-781. doi: 10.1038/35001596

Dozois, C. M., Daigle, F., and Curtiss, R. 3rd. (2003). Identification of pathogenspecific and conserved genes expressed in vivo by an avian pathogenic Escherichia coli strain. Proc. Natl. Acad. Sci. U.S.A. 100, 247-252. doi: 10.1073/pnas.232686799

Drago-Serrano, M. E., Parra, S. G., and Manjarrez-Hernandez, H. A. (2006). EspC, an autotransporter protein secreted by enteropathogenic Escherichia coli (EPEC), displays protease activity on human hemoglobin. FEMS Microbiol. Lett. 265, 35-40. doi: 10.1111/j.1574-6968.2006.00463.x

Drazek, E. S., Hammack, C. A., and Schmitt, M. P. (2000). Corynebacterium diphtheriae genes required for acquisition of iron from haemin and haemoglobin are homologous to ABC haemin transporters. Mol. Microbiol. 36, 68-84. doi: 10.1046/j.1365-2958.2000.01818.x

Dryla, A., Gelbmann, D., Von Gabain, A., and Nagy, E. (2003). Identification of a novel iron regulated staphylococcal surface protein with haptoglobinhaemoglobin binding activity. Mol. Microbiol. 49, 37-53. doi: 10.1046/j.13652958.2003.03542.x

Dryla, A., Hoffmann, B., Gelbmann, D., Giefing, C., Hanner, M., Meinke, A., et al. (2007). High-affinity binding of the staphylococcal HarA protein to haptoglobin and hemoglobin involves a domain with an antiparallel eight-stranded betabarrel fold. J. Bacteriol. 189, 254-264. doi: 10.1128/JB.01366-06

Duffy, S. P., Shing, J., Saraon, P., Berger, L. C., Eiden, M. V., Wilde, A., et al. (2010). The Fowler syndrome-associated protein FLVCR2 is an importer of heme. Mol. Cell Biol. 30, 5318-5324. doi: 10.1128/MCB.00690-10

Eisendle, M., Oberegger, H., Zadra, I., and Haas, H. (2003). The siderophore system is essential for viability of Aspergillus nidulans: functional analysis of two genes encoding l-ornithine $\mathrm{N}$ 5-monooxygenase (sidA) and a non-ribosomal peptide synthetase (sidC). Mol. Microbiol. 49, 359-375. doi: 10.1046/j.13652958.2003.03586.x

Elhassanny, A. E., Anderson, E. S., Menscher, E. A., and Roop, R. M. 2nd. (2013). The ferrous iron transporter FtrABCD is required for the virulence of Brucella abortus 2308 in mice. Mol. Microbiol. 88, 1070-1082. doi: 10.1111/ mmi. 12242

Emery, T. (1982). Iron metabolism in humans and plants. Am. Sci. 70, 626-632.

Evans, R. W., Crawley, J. B., Joannou, C. L., and Sharma, N. D. (1999). "Iron proteins," in Iron and Infection - Molecular, Physiological and Clinical Aspects, 2nd Edn. eds J. J. Bullen and E. Griffiths (West Sussex: John Wiley \& Sons Ltd), $27-87$.

Evstatiev, R., and Gasche, C. (2012). Iron sensing and signalling. Gut 61, 933-952. doi: 10.1136/gut.2010.214312

Fabian, M., Solomaha, E., Olson, J. S., and Maresso, A. W. (2009). Heme transfer to the bacterial cell envelope occurs via a secreted hemophore in the Grampositive pathogen Bacillus anthracis. J. Biol. Chem. 284, 32138-32146. doi: 10.1074/jbc.M109.040915

Faraldo-Gomez, J. D., and Sansom, M. S. (2003). Acquisition of siderophores in gram-negative bacteria. Nat Rev Mol. Cell Biol. 4, 105-116. doi: $10.1038 / \mathrm{nrm} 1015$

Fecker, L., and Braun, V. (1983). Cloning and expression of the fhu genes involved in iron(III)-hydroxamate uptake by Escherichia coli. J. Bacteriol. 156, 1301-1314.
Felmlee, T., Pellett, S., and Welch, R. A. (1985). Nucleotide sequence of an Escherichia coli chromosomal hemolysin. J. Bacteriol. 163, 94-105.

Ferguson, A. D., and Deisenhofer, J. (2002). TonB-dependent receptors-structural perspectives. Biochim. Biophys. Acta 1565, 318-332. doi: 10.1016/S00052736(02)00578-3

Fetherston, J. D., Kirillina, O., Bobrov, A. G., Paulley, J. T., and Perry, R. D. (2010). The yersiniabactin transport system is critical for the pathogenesis of bubonic and pneumonic plague. Infect. Immun. 78, 2045-2052. doi: 10.1128/IAI. 01236-09

Finberg, K. E. (2013). Regulation of systemic iron homeostasis. Curr. Opin. Hematol. 20, 208-214. doi: 10.1097/MOH.0b013e32835f5a47

Fischbach, F. A., and Anderegg, J. W. (1965). An x-ray scattering study of ferritin and apoferritin. J. Mol. Biol. 14, 458-473. doi: 10.1016/S0022-2836(65)80196-6

Fischbach, M. A., Lin, H., Zhou, L., Yu, Y., Abergel, R. J., Liu, D. R., et al. (2006). The pathogen-associated iroA gene cluster mediates bacterial evasion of lipocalin 2. Proc. Natl. Acad. Sci. U.S.A. 103, 16502-16507. doi: 10.1073/pnas.0604636103

Fisher, M., Huang, Y. S., Li, X., McIver, K. S., Toukoki, C., and Eichenbaum, Z. (2008). Shr is a broad-spectrum surface receptor that contributes to adherence and virulence in group A streptococcus. Infect. Immun. 76, 5006-5015. doi: 10.1128/IAI.00300-08

Fleischmann, R. D., Adams, M. D., White, O., Clayton, R. A., Kirkness, E. F., Kerlavage, A. R., et al. (1995). Whole-genome random sequencing and assembly of Haemophilus influenzae Rd. Science 269, 496-512. doi: 10.1126/science. 7542800

Fleming, M. D., Romano, M. A., Su, M. A., Garrick, L. M., Garrick, M. D., and Andrews, N. C. (1998). Nramp2 is mutated in the anemic Belgrade (b) rat: evidence of a role for Nramp2 in endosomal iron transport. Proc. Natl. Acad. Sci. U.S.A. 95, 1148-1153. doi: 10.1073/pnas.95.3.1148

Fleming, M. D., Trenor, C. C. 3rd., Su, M. A., Foernzler, D., Beier, D. R., Dietrich, W. F., and Andrews, N. C. (1997). Microcytic anaemia mice have a mutation in Nramp2, a candidate iron transporter gene. Nat. Genet. 16, 383-386.

Fleming, R. E., Migas, M. C., Holden, C. C., Waheed, A., Britton, R. S., Tomatsu, S., et al. (2000). Transferrin receptor 2: continued expression in mouse liver in the face of iron overload and in hereditary hemochromatosis. Proc. Natl. Acad. Sci. U.S.A. 97, 2214-2219. doi: 10.1073/pnas.040548097

Flo, T. H., Smith, K. D., Sato, S., Rodriguez, D. J., Holmes, M. A., Strong, R. K., et al. (2004). Lipocalin 2 mediates an innate immune response to bacterial infection by sequestrating iron. Nature 432, 917-921. doi: 10.1038/nature03104

Fluckinger, M., Haas, H., Merschak, P., Glasgow, B. J., and Redl, B. (2004). Human tear lipocalin exhibits antimicrobial activity by scavenging microbial siderophores. Antimicrob. Agents Chemother. 48, 3367-3372. doi: 10.1128/AAC.48.9.3367-3372.2004

Foster, L. A. (2002). Utilization and cell-surface binding of hemin by Histoplasma capsulatum. Can J Microbiol 48, 437-442. doi: 10.1139/w02-037

Fournier, C., Smith, A., and Delepelaire, P. (2011). Haem release from haemopexin by HxuA allows Haemophilus influenzae to escape host nutritional immunity. Mol. Microbiol. 80, 133-148. doi: 10.1111/j.1365-2958.2011.07562.x

Francis, J., Macturk, H. M., Madinaveitia, J., and Snow, G. A. (1953). Mycobactin, a growth factor for Mycobacterium johnei. I. Isolation from Mycobacterium phlei. Biochem. J. 55, 596-607.

Francis, J., Madinaveitia, J., Macturk, H. M., and Snow, G. A. (1949). Isolation from acid-fast bacteria of a growth-factor for Mycobacterium johnei and of a precursor of phthiocol. Nature 163, 365. doi: 10.1038/163365b0

Freestone, P. P., Haigh, R. D., Williams, P. H., and Lyte, M. (2003). Involvement of enterobactin in norepinephrine-mediated iron supply from transferrin to enterohaemorrhagic Escherichia coli. FEMS Microbiol. Lett. 222, 39-43. doi: 10.1016/S0378-1097(03)00243-X

Freestone, P. P., Hirst, R. A., Sandrini, S. M., Sharaff, F., Fry, H., Hyman, S., et al. (2012). Pseudomonas aeruginosa-catecholamine inotrope interactions: a contributory factor in the development of ventilator-associated pneumonia? Chest 142, 1200-1210. doi: 10.1378/chest.11-2614

Freestone, P. P., Lyte, M., Neal, C. P., Maggs, A. F., Haigh, R. D., and Williams, P. H. (2000). The mammalian neuroendocrine hormone norepinephrine supplies iron for bacterial growth in the presence of transferrin or lactoferrin. J. Bacteriol. 182, 6091-6098. doi: 10.1128/JB.182.21.6091-6098.2000

Freestone, P. P., Williams, P. H., Haigh, R. D., Maggs, A. F., Neal, C. P., and Lyte, M. (2002). Growth stimulation of intestinal commensal Escherichia coli by catecholamines: a possible contributory factor in trauma-induced sepsis. Shock 18, 465-470. doi: 10.1097/00024382-200211000-00014 
Ganz, T. (2012). Macrophages and systemic iron homeostasis. J. Innate Immun. 4, 446-453. doi: 10.1159/000336423

Garenaux, A., Caza, M., and Dozois, C. M. (2011). The Ins and Outs of siderophore mediated iron uptake by extra-intestinal pathogenic Escherichia coli. Vet. Microbiol. 153, 89-98. doi: 10.1016/j.vetmic.2011.05.023

Garibaldi, J. A., and Neilands, J. B. (1956). Formation of iron-binding compounds by micro-organisms. Nature 177, 526-527. doi: 10.1038/177526a0

Glaser, P., Sakamoto, H., Bellalou, J., Ullmann, A., and Danchin, A. (1988). Secretion of cyclolysin, the calmodulin-sensitive adenylate cyclase-haemolysin bifunctional protein of Bordetella pertussis. EMBO J. 7, 3997-4004.

Gobin, J., and Horwitz, M. A. (1996). Exochelins of Mycobacterium tuberculosis remove iron from human iron-binding proteins and donate iron to mycobactins in the M. tuberculosis cell wall. J. Exp. Med. 183, 1527-1532. doi: 10.1084/jem.183.4.1527

Goetz, D. H., Holmes, M. A., Borregaard, N., Bluhm, M. E., Raymond, K. N., and Strong, R. K. (2002). The neutrophil lipocalin NGAL is a bacteriostatic agent that interferes with siderophore-mediated iron acquisition. Mol. Cell 10, 1033-1043. doi: 10.1016/S1097-2765(02)00708-6

Griffiths, E. (1999). "Iron in biological systems," in Iron and Infection, 2nd Edn, eds J. J. Bullen and E. Griffiths. (West Sussex: John Wiley and Sons Ltd), 1-26.

Grosse, C., Scherer, J., Koch, D., Otto, M., Taudte, N., and Grass, G. (2006). A new ferrous iron-uptake transporter, EfeU (YcdN), from Escherichia coli. Mol. Microbiol. 62, 120-131. doi: 10.1111/j.1365-2958.2006.05326.x

Gunshin, H., Mackenzie, B., Berger, U. V., Gunshin, Y., Romero, M. F., Boron, W. F., et al. (1997). Cloning and characterization of a mammalian proton-coupled metal-ion transporter. Nature 388, 482-488. doi: 10.1038/41343

Haas, H. (2012). Iron - a key nexus in the virulence of Aspergillus fumigatus. Front. Microbiol. 3:28. doi: 10.3389/fmicb.2012.00028

Haas, H., Eisendle, M., and Turgeon, B. G. (2008). Siderophores in fungal physiology and virulence. Annu. Rev. Phytopathol. 46, 149-187. doi: 10.1146/annurev.phyto.45.062806.094338

Haas, H., Schoeser, M., Lesuisse, E., Ernst, J. F., Parson, W., Abt, B., et al. (2003). Characterization of the Aspergillus nidulans transporters for the siderophores enterobactin and triacetylfusarinine C. Biochem. J. 371, 505-513. doi: 10.1042/BJ20021685

Hagan, E. C., and Mobley, H. L. (2009). Haem acquisition is facilitated by a novel receptor Hma and required by uropathogenic Escherichia coli for kidney infection. Mol. Microbiol. 71, 79-91. doi: 10.1111/j.1365-2958.2008.06509.x

Hammacott, J. E., Williams, P. H., and Cashmore, A. M. (2000). Candida albicans CFL1 encodes a functional ferric reductase activity that can rescue a Saccharomyces cerevisiae fre1 mutant. Microbiology 146(Pt 4), 869-876.

Hanson, M. S., and Hansen, E. J. (1991). Molecular cloning, partial purification, and characterization of a haemin-binding lipoprotein from Haemophilus influenzae type b. Mol. Microbiol. 5, 267-278. doi: 10.1111/j.1365-2958.1991.tb02107.x

Hanson, M. S., Pelzel, S. E., Latimer, J., Muller-Eberhard, U., and Hansen, E. J. (1992a). Identification of a genetic locus of Haemophilus influenzae type b necessary for the binding and utilization of heme bound to human hemopexin. Proc. Natl. Acad. Sci. U.S.A. 89, 1973-1977. doi: 10.1073/pnas.89.5.1973

Hanson, M. S., Slaughter, C., and Hansen, E. J. (1992b). The hbpA gene of Haemophilus influenzae type $\mathrm{b}$ encodes a heme-binding lipoprotein conserved among heme-dependent Haemophilus species. Infect. Immun. 60, 2257-2266.

Hantke, K. (1981). Regulation of ferric iron transport in Escherichia coli K12: isolation of a constitutive mutant. Mol. Gen. Genet. 182, 288-292. doi: 10.1007/BF00269672

Hantke, K. (1983). Identification of an iron uptake system specific for coprogen and rhodotorulic acid in Escherichia coli K12. Mol. Gen. Genet. 191, 301-306. doi: 10.1007/BF00334830

Hantke, K., Nicholson, G., Rabsch, W., and Winkelmann, G. (2003). Salmochelins, siderophores of Salmonella enterica and uropathogenic Escherichia coli strains, are recognized by the outer membrane receptor IroN. Proc. Natl. Acad. Sci. U.S.A. 100, 3677-3682. doi: 10.1073/pnas.0737682100

Harris, W. R., Carrano, C. J., Cooper, S. R., Sofen, S. R., Avdeef, A. E., Mcardle, J. V., et al. (1979). Coordination chemistry of microbial iron transport compounds. 19. Stability constants and electrochemical behavior of ferric enterobactin and model complexes. J. Am. Chem. Soc. 101, 6097-6104. doi: 10.1021/ ja00514a037

Henderson, D. P., and Payne, S. M. (1994). Vibrio cholerae iron transport systems: roles of heme and siderophore iron transport in virulence and identification of a gene associated with multiple iron transport systems. Infect. Immun. 62, 5120-5125.

Hentze, M. W., Muckenthaler, M. U., Galy, B., and Camaschella, C. (2010). Two to tango: regulation of Mammalian iron metabolism. Cell 142, 24-38. doi: 10.1016/j.cell.2010.06.028

Hesseltine, C. W., Pidacks, C., Whitehill, A. R., Bohonos, N., Hutchings, B. L., and Williams, J. H. (1952). Coprogen, a new growth factor for coprophylic fungi. J. Am. Chem. Soc. 74, 1362-1362. doi: 10.1021/ja01125a525

Heymann, P., Gerads, M., Schaller, M., Dromer, F., Winkelmann, G., and Ernst, J. F. (2002). The siderophore iron transporter of Candida albicans (Sitlp/Arn lp) mediates uptake of ferrichrome-type siderophores and is required for epithelial invasion. Infect. Immun. 70, 5246-5255. doi: 10.1128/IAI.70.9.52465255.2002

Hissen, A. H., Chow, J. M., Pinto, L. J., and Moore, M. M. (2004). Survival of Aspergillus fumigatus in serum involves removal of iron from transferrin: the role of siderophores. Infect. Immun. 72, 1402-1408. doi: 10.1128/IAI.72.3.14021408.2004

Hissen, A. H., and Moore, M. M. (2005). Site-specific rate constants for iron acquisition from transferrin by the Aspergillus fumigatus siderophores N,'N,"N"'triacetylfusarinine $\mathrm{C}$ and ferricrocin. J. Biol. Inorg. Chem. 10, 211-220. doi: 10.1007/s00775-005-0630-z

Hoare, R. J., Harrison, P. M., and Hoy, T. G. (1975). Structure of horse-spleen apoferritin at 6 angstom resolution. Nature 255, 653-654. doi: 10.1038/255653a0

Hornung, J. M., Jones, H. A., and Perry, R. D. (1996). The hmu locus of Yersinia pestis is essential for utilization of free haemin and haem-protein complexes as iron sources. Mol. Microbiol. 20, 725-739. doi: 10.1111/j.13652958.1996.tb02512.x

Hu, G., Caza, M., Cadieux, B., Chan, V., Liu, V., and Kronstad, J. (2013). Cryptococcus neoformans requires the ESCRT protein Vps23 for iron acquisition from heme, for capsule formation, and for virulence. Infect. Immun. 81, 292-302. doi: 10.1128/IAI.01037-12

Hu, H. Y., and Aisen, P. (1978). Molecular characteristics of the transferrinreceptor complex of the rabbit reticulocyte. J. Supramol. Struct. 8, 349-360. doi: $10.1002 /$ jss. 400080312

Hurley, J. H., and Emr, S. D. (2006). The ESCRT complexes: structure and mechanism of a membrane-trafficking network. Annu. Rev. Biophys. Biomol. Struct. 35, 277-298. doi: 10.1146/annurev.biophys.35.040405.102126

Hvidberg, V., Maniecki, M. B., Jacobsen, C., Hojrup, P., Moller, H. J., and Moestrup, S. K. (2005). Identification of the receptor scavenging hemopexin-heme complexes. Blood 106, 2572-2579. doi: 10.1182/blood-2005-03-1185

Idei, A., Kawai, E., Akatsuka, H., and Omori, K. (1999). Cloning and characterization of the Pseudomonas fluorescens ATP-binding cassette exporter, HasDEF, for the heme acquisition protein HasA. J. Bacteriol. 181, 7545-7551.

Ilbert, M., and Bonnefoy, V. (2013). Insight into the evolution of the iron oxidation pathways. Biochim. Biophys. Acta 1827, 161-175. doi: 10.1016/j.bbabio. 2012.10.001

Imlay, J. A. (2003). Pathways of oxidative damage. Annu. Rev. Microbiol. 57, 395-418. doi: 10.1146/annurev.micro.57.030502.090938

Izadi-Pruneyre, N., Huche, F., Lukat-Rodgers, G. S., Lecroisey, A., Gilli, R., Rodgers, K. R., et al. (2006). The heme transfer from the soluble HasA hemophore to its membrane-bound receptor HasR is driven by protein-protein interaction from a high to a lower affinity binding site. J. Biol. Chem. 281, 25541-25550. doi: 10.1074/jbc.M603698200

Jacobson, E. S., Goodner, A. P., and Nyhus, K. J. (1998). Ferrous iron uptake in Cryptococcus neoformans. Infect. Immun. 66, 4169-4175.

Jin, B., Newton, S. M., Shao, Y., Jiang, X., Charbit, A., and Klebba, P. E. (2006). Iron acquisition systems for ferric hydroxamates, haemin and haemoglobin in Listeria monocytogenes. Mol. Microbiol. 59, 1185-1198. doi: 10.1111/j.13652958.2005.05015.x

Jin, H., Ren, Z., Pozsgay, J. M., Elkins, C., Whitby, P. W., Morton, D. J., et al. (1996). Cloning of a DNA fragment encoding a heme-repressible hemoglobinbinding outer membrane protein from Haemophilus influenzae. Infect. Immun. $64,3134-3141$.

Jung, W. H., Hu, G., Kuo, W., and Kronstad, J. W. (2009). Role of ferroxidases in iron uptake and virulence of Cryptococcus neoformans. Eukaryot. Cell 8, 1511-1520. doi: 10.1128/EC.00166-09

Jung, W. H., and Kronstad, J. W. (2008). Iron and fungal pathogenesis: a case study with Cryptococcus neoformans. Cell Microbiol. 10, 277-284. doi: 10.1111/j.14625822.2007.01077.x 
Jung, W. H., Sham, A., Lian, T., Singh, A., Kosman, D. J., and Kronstad, J. W. (2008). Iron source preference and regulation of iron uptake in Cryptococcus neoformans. PLoS Pathog. 4:e45. doi: 10.1371/journal.ppat.0040045

Kammler, M., Schon, C., and Hantke, K. (1993). Characterization of the ferrous iron uptake system of Escherichia coli. J. Bacteriol. 175, 6212-6219.

Kawabata, H., Yang, R., Hirama, T., Vuong, P. T., Kawano, S., Gombart, A. F., et al. (1999). Molecular cloning of transferrin receptor 2. A new member of the transferrin receptor-like family. J. Biol. Chem. 274, 20826-20832. doi: 10.1074/jbc.274.30.20826

Khun, H. H., Kirby, S. D., and Lee, B. C. (1998). A Neisseria meningitidis fbpABC mutant is incapable of using nonheme iron for growth. Infect. Immun. 66, 2330-2336.

Knight, S. A., Lesuisse, E., Stearman, R., Klausner, R. D., and Dancis, A. (2002). Reductive iron uptake by Candida albicans: role of copper, iron and the TUP1 regulator. Microbiology 148, 29-40.

Knight, S. A., Vilaire, G., Lesuisse, E., and Dancis, A. (2005). Iron acquisition from transferrin by Candida albicans depends on the reductive pathway. Infect. Immun. 73, 5482-5492. doi: 10.1128/IAI.73.9.54825492.2005

Kochan, I. (1973). The role of iron in bacterial infections, with special consideration of host-tubercle bacillus interaction. Curr. Top. Microbiol. Immunol. 60, 1-30. doi: 10.1007/978-3-642-65502-9_1

Konopka, K., Bindereif, A., and Neilands, J. B. (1982). Aerobactin-mediated utilization of transferrin iron. Biochemistry 21, 6503-6508. doi: 10.1021/ bi00268a028

Kornitzer, D. (2009). Fungal mechanisms for host iron acquisition. Curr. Opin. Microbiol. 12, 377-383. doi: 10.1016/j.mib.2009.05.005

Kortman, G. A., Boleij, A., Swinkels, D. W., and Tjalsma, H. (2012). Iron availability increases the pathogenic potential of Salmonella typhimurium and other enteric pathogens at the intestinal epithelial interface. PLoS ONE 7:e29968. doi: 10.1371/journal.pone.0029968

Kosman, D. J. (2003). Molecular mechanisms of iron uptake in fungi. Mol. Microbiol. 47, 1185-1197. doi: 10.1046/j.1365-2958.2003.03368.x

Kragl, C., Schrettl, M., Abt, B., Sarg, B., Lindner, H. H., and Haas, H. (2007). EstB-mediated hydrolysis of the siderophore triacetylfusarinine C optimizes iron uptake of Aspergillus fumigatus. Eukaryot. Cell 6, 1278-1285. doi: 10.1128/EC.00066-07

Krieg, S., Huche, F., Diederichs, K., Izadi-Pruneyre, N., Lecroisey, A., Wandersman, C., et al. (2009). Heme uptake across the outer membrane as revealed by crystal structures of the receptor-hemophore complex. Proc. Natl. Acad. Sci. U.S.A. 106, 1045-1050. doi: 10.1073/pnas.0809406106

Kristiansen, M., Graversen, J. H., Jacobsen, C., Sonne, O., Hoffman, H. J., Law, S. K., et al. (2001). Identification of the haemoglobin scavenger receptor. Nature 409, 198-201. doi: 10.1038/35051594

Kronstad, J. W., Hu, G., and Jung, W. H. (2013). An encapsulation of iron homeostasis and virulence in Cryptococcus neoformans. Trends Microbiol 21, 457-465. doi: 10.1016/j.tim.2013.05.007

Kulkarni, R. D., Kelkar, H. S., and Dean, R. A. (2003). An eight-cysteine-containing CFEM domain unique to a group of fungal membrane proteins. Trends Biochem. Sci. 28, 118-121. doi: 10.1016/S0968-0004(03)00025-2

Lahoz, E., Pisacane, A., Iannaccone, M., Palumbo, D., and Capparelli, R. (2008). Fungistatic activity of iron-free bovin lactoferrin against several fungal plant pathogens and antagonists. Nat. Prod. Res. 22, 955-961. doi: 10.1080/14786410701650253

Langman, L., Young, I. G., Frost, G. E., Rosenberg, H., and Gibson, F. (1972). Enterochelin system of iron transport in Escherichia coli: mutations affecting ferric-enterochelin esterase. J. Bacteriol. 112, 1142-1149.

Lansky, I. B., Lukat-Rodgers, G. S., Block, D., Rodgers, K. R., Ratliff, M., and Wilks, A. (2006). The cytoplasmic heme-binding protein (PhuS) from the heme uptake system of Pseudomonas aeruginosa is an intracellular heme-trafficking protein to the delta-regioselective heme oxygenase. J. Biol. Chem. 281, 13652-13662. doi: 10.1074/jbc.M600824200

Larson, J. A., Howie, H. L., and So, M. (2004). Neisseria meningitidis accelerates ferritin degradation in host epithelial cells to yield an essential iron source. Mol. Microbiol. 53, 807-820. doi: 10.1111/j.1365-2958.2004.04169.x

Latunde-Dada, G. O., Simpson, R. J., and McKie, A. T. (2008). Duodenal cytochrome B expression stimulates iron uptake by human intestinal epithelial cells. J. Nutr. 138, 991-995.
Lau, C. K., Ishida, H., Liu, Z., and Vogel, H. J. (2013). Solution structure of Escherichia coli FeoA and its potential role in bacterial ferrous iron transport. J. Bacteriol. 195, 46-55. doi: 10.1128/JB.01121-12

Leal, S. M. Jr., Roy, S., Vareechon, C., Carrion, S., Clark, H., Lopez-Berges, M. S., et al. (2013). Targeting iron acquisition blocks infection with the fungal pathogens Aspergillus fumigatus and Fusarium oxysporum. PLoS Pathog. 9:e1003436. doi: 10.1371/journal.ppat.1003436

Lei, B., Liu, M., Voyich, J. M., Prater, C. I., Kala, S. V., Deleo, F. R., et al. (2003). Identification and characterization of HtsA, a second heme-binding protein made by Streptococcus pyogenes. Infect. Immun. 71, 5962-5969. doi: 10.1128/IAI.71.10.5962-5969.2003

Lei, B., Smoot, L. M., Menning, H. M., Voyich, J. M., Kala, S. V., Deleo, F. R., et al. (2002). Identification and characterization of a novel heme-associated cell surface protein made by Streptococcus pyogenes. Infect. Immun. 70, 4494-4500. doi: 10.1128/IAI.70.8.4494-4500.2002

Letoffe, S., Delepelaire, P., and Wandersman, C. (2006). The housekeeping dipeptide permease is the Escherichia coli heme transporter and functions with two optional peptide binding proteins. Proc. Natl. Acad. Sci. U.S.A. 103, 12891-12896. doi: 10.1073/pnas.0605440103

Letoffe, S., Ghigo, J. M., and Wandersman, C. (1994a). Iron acquisition from heme and hemoglobin by a Serratia marcescens extracellular protein. Proc. Natl. Acad. Sci. U.S.A. 91, 9876-9880. doi: 10.1073/pnas.91.21.9876

Letoffe, S., Ghigo, J. M., and Wandersman, C. (1994b). Secretion of the Serratia marcescens HasA protein by an ABC transporter. J. Bacteriol. 176, 5372-5377.

Letoffe, S., Nato, F., Goldberg, M. E., and Wandersman, C. (1999). Interactions of HasA, a bacterial haemophore, with haemoglobin and with its outer membrane receptor HasR. Mol. Microbiol. 33, 546-555. doi: 10.1046/j.13652958.1999.01499.x

Letoffe, S., Redeker, V., and Wandersman, C. (1998). Isolation and characterization of an extracellular haem-binding protein from Pseudomonas aeruginosa that shares function and sequence similarities with the Serratia marcescens HasA haemophore. Mol. Microbiol. 28, 1223-1234. doi: 10.1046/j.13652958.1998.00885.X

Lewis, J. P., Plata, K., Yu, F., Rosato, A., and Anaya, C. (2006). Transcriptional organization, regulation and role of the Porphyromonas gingivalis W83 hmu haemin-uptake locus. Microbiology 152, 3367-3382. doi: 10.1099/ mic.0.29011-0

Lewis, L. A., and Dyer, D. W. (1995). Identification of an iron-regulated outer membrane protein of Neisseria meningitidis involved in the utilization of hemoglobin complexed to haptoglobin. J. Bacteriol. 177, 1299-1306.

Lewis, L. A., Gipson, M., Hartman, K., Ownbey, T., Vaughn, J., and Dyer, D. W. (1999). Phase variation of HpuAB and HmbR, two distinct haemoglobin receptors of Neisseria meningitidis DNM2. Mol. Microbiol. 32, 977-989. doi: 10.1046/j.1365-2958.1999.01409.x

Lewis, L. A., Gray, E., Wang, Y. P., Roe, B. A., and Dyer, D. W. (1997). Molecular characterization of hpuAB, the haemoglobin-haptoglobin-utilization operon of Neisseria meningitidis. Mol. Microbiol. 23, 737-749. doi: 10.1046/j.13652958.1997.2501619.x

Lin, H., Fischbach, M. A., Liu, D. R., and Walsh, C. T. (2005). In vitro characterization of salmochelin and enterobactin trilactone hydrolases IroD, IroE, and Fes. J Am Chem Soc 127, 11075-11084. doi: 10.1021/ja0522027

Liu, M., Tanaka, W. N., Zhu, H., Xie, G., Dooley, D. M., and Lei, B. (2008). Direct hemin transfer from IsdA to IsdC in the iron-regulated surface determinant (Isd) heme acquisition system of Staphylococcus aureus. J. Biol. Chem. 283, 6668-6676. doi: 10.1074/jbc.M708372200

Liu, X., Olczak, T., Guo, H. C., Dixon, D. W., and Genco, C. A. (2006). Identification of amino acid residues involved in heme binding and hemoprotein utilization in the Porphyromonas gingivalis heme receptor HmuR. Infect. Immun. 74, 1222-1232. doi: 10.1128/IAI.74.2.1222-1232.2006

Lochead, A. G., Burton, M. O., and Thexton, R. H. (1952). A bacterial growthfactor synthesized by a soil bacterium. Nature 170, 282. doi: 10.1038/170 $282 \mathrm{a} 0$

Lu, C., Xie, G., Liu, M., Zhu, H., and Lei, B. (2012). Direct heme transfer reactions in the Group A Streptococcus heme acquisition pathway. PLoS ONE 7:e37556. doi: 10.1371/journal.pone.0037556

Ludwig, A., Von Rhein, C., Bauer, S., Huttinger, C., and Goebel, W. (2004). Molecular analysis of cytolysin A (ClyA) in pathogenic Escherichia coli strains. J. Bacteriol. 186, 5311-5320. doi: 10.1128/JB.186.16.5311-5320.2004 
Lundrigan, M. D., and Kadner, R. J. (1986). Nucleotide sequence of the gene for the ferrienterochelin receptor FepA in Escherichia coli. Homology among outer membrane receptors that interact with TonB. J. Biol. Chem. 261, 10797-10801.

Lyte, M., Freestone, P. P., Neal, C. P., Olson, B. A., Haigh, R. D., Bayston, R., et al. (2003). Stimulation of Staphylococcus epidermidis growth and biofilm formation by catecholamine inotropes. Lancet 361, 130-135. doi: 10.1016/S01406736(03)12231-3

Manns, J. M., Mosser, D. M., and Buckley, H. R. (1994). Production of a hemolytic factor by Candida albicans. Infect. Immun. 62, 5154-5156.

Maresso, A. W., Chapa, T. J., and Schneewind, O. (2006). Surface protein IsdC and Sortase B are required for heme-iron scavenging of Bacillus anthracis. J. Bacteriol. 188, 8145-8152. doi: 10.1128/JB.01011-06

Maresso, A. W., Garufi, G., and Schneewind, O. (2008). Bacillus anthracis secretes proteins that mediate heme acquisition from hemoglobin. PLoS Pathog. 4:e1000132. doi: 10.1371/journal.ppat.1000132

Mason, K. M., Raffel, F. K., Ray, W. C., and Bakaletz, L. O. (2011). Heme utilization by nontypeable Haemophilus influenzae is essential and dependent on Sap transporter function. J. Bacteriol. 193, 2527-2535. doi: 10.1128/JB.01313-10

Mazmanian, S. K., Skaar, E. P., Gaspar, A. H., Humayun, M., Gornicki, P., Jelenska, J., et al. (2003). Passage of heme-iron across the envelope of Staphylococcus aureus. Science 299, 906-909. doi: 10.1126/science.1081147

Mazurier, J., and Spik, G. (1980). Comparative study of the iron-binding properties of human transferrins. I. Complete and sequential iron saturation and desaturation of the lactotransferrin. Biochim. Biophys. Acta 629, 399-408. doi: 10.1016/0304-4165(80)90112-9

McCance, R. A., and Widdowson, E. M. (1937). Absorption and excretion of iron. Lancet 230, 680-684. doi: 10.1016/S0140-6736(00)56469-1

McKie, A. T., Barrow, D., Latunde-Dada, G. O., Rolfs, A., Sager, G., Mudaly, E., et al. (2001). An iron-regulated ferric reductase associated with the absorption of dietary iron. Science 291, 1755-1759. doi: 10.1126/science.1057206

Meiwes, J., Fiedler, H. P., Haag, H., Zahner, H., Konetschny-Rapp, S., and Jung, G. (1990). Isolation and characterization of staphyloferrin A, a compound with siderophore activity from Staphylococcus hyicus DSM 20459. FEMS Microbiol. Lett. 55, 201-205. doi: 10.1111/j.1574-6968.1990.tb13863.x

Methner, U., Rabsch, W., Reissbrodt, R., and Williams, P. H. (2008). Effect of norepinephrine on colonisation and systemic spread of Salmonella enterica in infected animals: role of catecholate siderophore precursors and degradation products. Int J. Med. Microbiol. 298, 429-439. doi: 10.1016/j.ijmm.2007.07.013

Miethke, M., Klotz, O., Linne, U., May, J. J., Beckering, C. L., and Marahiel, M. A. (2006). Ferri-bacillibactin uptake and hydrolysis in Bacillus subtilis. Mol. Microbiol. 61, 1413-1427. doi: 10.1111/j.1365-2958.2006.05321.x

Miethke, M., and Marahiel, M. A. (2007). Siderophore-based iron acquisition and pathogen control. Microbiol. Mol. Biol. Rev. 71, 413-451. doi: 10.1128/MMBR.00012-07

Miethke, M., Monteferrante, C. G., Marahiel, M. A., and Van Dijl, J. M. (2013). The Bacillus subtilis EfeUOB transporter is essential for high-affinity acquisition of ferrous and ferric iron. Biochim. Biophys. Acta 1833, 2267-2278. doi: 10.1016/j.bbamcr.2013.05.027

Miethke, M., and Skerra, A. (2010). Neutrophil gelatinase-associated lipocalin expresses antimicrobial activity by interfering with L-norepinephrine-mediated bacterial iron acquisition. Antimicrob. Agents Chemother. 54, 1580-1589. doi: 10.1128/AAC.01158-09

Moors, M. A., Stull, T. L., Blank, K. J., Buckley, H. R., and Mosser, D. M. (1992). A role for complement receptor-like molecules in iron acquisition by Candida albicans. J. Exp. Med. 175, 1643-1651. doi: 10.1084/jem.175.6.1643

Morrissey, J. A., Cockayne, A., Hill, P. J., and Williams, P. (2000). Molecular cloning and analysis of a putative siderophore ABC transporter from Staphylococcus aureus. Infect. Immun. 68, 6281-6288. doi: 10.1128/IAI.68.11.6281-6288.2000

Morton, D. J., Seale, T. W., Bakaletz, L. O., Jurcisek, J. A., Smith, A., Vanwagoner, T. M., et al. (2009a). The heme-binding protein (HbpA) of Haemophilus influenzae as a virulence determinant. Int J. Med. Microbiol. 299, 479-488. doi: 10.1016/j.ijmm.2009.03.004

Morton, D. J., Seale, T. W., Vanwagoner, T. M., Whitby, P. W., and Stull, T. L. (2009b). The dppBCDF gene cluster of Haemophilus influenzae: role in heme utilization. BMC Res. Notes 2:166. doi: 10.1186/1756-0500-2-166

Morton, D. J., Seale, T. W., Madore, L. L., Vanwagoner, T. M., Whitby, P. W., and Stull, T. L. (2007a). The haem-haemopexin utilization gene cluster (hxuCBA) as a virulence factor of Haemophilus influenzae. Microbiology 153, 215-224. doi: 10.1099/mic.0.2006/000190-0
Morton, D. J., Smith, A., Vanwagoner, T. M., Seale, T. W., Whitby, P. W., and Stull, T. L. (2007b). Lipoprotein e (P4) of Haemophilus influenzae: role in heme utilization and pathogenesis. Microbes Infect. 9, 932-939. doi: 10.1016/j.micinf.2007. 03.013

Morton, D. J., Smith, A., Ren, Z., Madore, L. L., Vanwagoner, T. M., Seale, T. W., et al. (2004). Identification of a haem-utilization protein (Hup) in Haemophilus influenzae. Microbiology 150, 3923-3933. doi: 10.1099/mic.0. 27238-0

Morton, D. J., Whitby, P. W., Jin, H., Ren, Z., and Stull, T. L. (1999). Effect of multiple mutations in the hemoglobin- and hemoglobin-haptoglobin-binding proteins, HgpA, HgpB, and HgpC, of Haemophilus influenzae type b. Infect. Immun. 67, 2729-2739.

Muryoi, N., Tiedemann, M. T., Pluym, M., Cheung, J., Heinrichs, D. E., and Stillman, M. J. (2008). Demonstration of the iron-regulated surface determinant (Isd) heme transfer pathway in Staphylococcus aureus. J. Biol. Chem. 283, 28125-28136. doi: 10.1074/jbc.M802171200

Navarathna, D. H., and Roberts, D. D. (2010). Candida albicans heme oxygenase and its product $\mathrm{CO}$ contribute to pathogenesis of candidemia and alter systemic chemokine and cytokine expression. Free Radic. Biol. Med. 49, 1561-1573. doi: 10.1016/j.freeradbiomed.2010.08.020

Neal, C. P., Freestone, P. P., Maggs, A. F., Haigh, R. D., Williams, P. H., and Lyte, M. (2001). Catecholamine inotropes as growth factors for Staphylococcus epidermidis and other coagulase-negative staphylococci. FEMS Microbiol. Lett. 194, 163-169. doi: 10.1111/j.1574-6968.2001.tb09463.x

Neilands, J. B. (1957). Some aspects of microbial iron metabolism. Bacteriol. Rev. 21, 101-111.

Nemeth, E., Tuttle, M. S., Powelson, J., Vaughn, M. B., Donovan, A., Ward, D. M., et al. (2004). Hepcidin regulates cellular iron efflux by binding to ferroportin and inducing its internalization. Science 306, 2090-2093. doi: 10.1126/science. 1104742

Noinaj, N., Buchanan, S. K., and Cornelissen, C. N. (2012a). The transferrin-iron import system from pathogenic Neisseria species. Mol. Microbiol. 86, 246-257. doi: $10.1111 / \mathrm{mmi} .12002$

Noinaj, N., Easley, N. C., Oke, M., Mizuno, N., Gumbart, J., Boura, E., et al. (2012b). Structural basis for iron piracy by pathogenic Neisseria. Nature 483, 53-58. doi: 10.1038/nature10823

Nygaard, T. K., Blouin, G. C., Liu, M., Fukumura, M., Olson, J. S., Fabian, M., et al. (2006). The mechanism of direct heme transfer from the streptococcal cell surface protein Shp to HtsA of the HtsABC transporter. J. Biol. Chem. 281, 20761-20771. doi: 10.1074/jbc.M601832200

Nyhus, K. J., Wilborn, A. T., and Jacobson, E. S. (1997). Ferric iron reduction by Cryptococcus neoformans. Infect. Immun. 65, 434-438.

Occhino, D. A., Wyckoff, E. E., Henderson, D. P., Wrona, T. J., and Payne, S. M. (1998). Vibrio cholerae iron transport: haem transport genes are linked to one of two sets of tonB, exbB, exbD genes. Mol. Microbiol. 29, 1493-1507. doi: 10.1046/j.1365-2958.1998.01034.x

Ochsner, U. A., Johnson, Z., and Vasil, M. L. (2000). Genetics and regulation of two distinct haem-uptake systems, phu and has, in Pseudomonas aeruginosa. Microbiology 146(Pt 1), 185-198.

O'Brien, I. G., and Gibson, F. (1970). The structure of enterochelin and related 2,3dihydroxy-N-benzoylserine conjugates from Escherichia coli. Biochim. Biophys. Acta 215, 393-402.

O’Donnell, P. M., Aviles, H., Lyte, M., and Sonnenfeld, G. (2006). Enhancement of in vitro growth of pathogenic bacteria by norepinephrine: importance of inoculum density and role of transferrin. Appl. Environ. Microbiol. 72, 5097-5099. doi: 10.1128/AEM.00075-06

Ohgami, R. S., Campagna, D. R., Greer, E. L., Antiochos, B., McDonald, A., Chen, J., et al. (2005). Identification of a ferrireductase required for efficient transferrin-dependent iron uptake in erythroid cells. Nat. Genet. 37, 1264-1269. doi: $10.1038 / \mathrm{ng} 1658$

Ohgami, R. S., Campagna, D. R., McDonald, A., and Fleming, M. D. (2006). The Steap proteins are metalloreductases. Blood 108, 1388-1394. doi: 10.1182/ blood-2006-02-003681

Okazaki, K., Asakura, M., Sugimoto, N., Hinenoya, A., and Yamasaki, S. (2009). Candida albicans, Cryptococcus neoformans or Aspergillus fumigatus induces an antifungal activity in mouse serum, which is different from transferrin. J. Vet. Med. Sci. 71, 1459-1464. doi: 10.1292/jvms.001459

Olczak, T., Dixon, D. W., and Genco, C. A. (2001). Binding specificity of the Porphyromonas gingivalis heme and hemoglobin receptor $\mathrm{HmuR}$, gingipain $\mathrm{K}$, 
and gingipain R1 for heme, porphyrins, and metalloporphyrins. J. Bacteriol. 183, 5599-5608. doi: 10.1128/JB.183.19.5599-5608.2001

Olczak, T., Sroka, A., Potempa, J., and Olczak, M. (2008). Porphyromonas gingivalis $\mathrm{HmuY}$ and HmuR: further characterization of a novel mechanism of heme utilization. Arch. Microbiol. 189, 197-210. doi: 10.1007/s00203-007-0309-7

O’Neill, M. J., Bhakta, M. N., Fleming, K. G., and Wilks, A. (2012). Induced fit on heme binding to the Pseudomonas aeruginosa cytoplasmic protein (PhuS) drives interaction with heme oxygenase (HemO). Proc. Natl. Acad. Sci. U.S.A. 109, 5639-5644. doi: 10.1073/pnas.1121549109

O'Neill, M. J., and Wilks, A. (2013). The P. aeruginosa heme binding protein PhuS is a heme oxygenase titratable regulator of heme uptake. ACS Chem. Biol. 8, 1794-1802. doi: 10.1021/cb400165b

Osaki, S., Johnson, D. A., and Frieden, E. (1966). The possible significance of the ferrous oxidase activity of ceruloplasmin in normal human serum. J. Biol. Chem. 241, 2746-2751.

Otto, B. R., Van Dooren, S. J., Nuijens, J. H., Luirink, J., and Oudega, B. (1998). Characterization of a hemoglobin protease secreted by the pathogenic Escherichia coli strain EB1. J. Exp. Med. 188, 1091-1103. doi: 10.1084/jem.188.6.1091

Otto, B. R., Verweij-Van Vught, A. M., and Maclaren, D. M. (1992). Transferrins and heme-compounds as iron sources for pathogenic bacteria. Crit Rev Microbiol 18, 217-233. doi: 10.3109/10408419209114559

Ouattara, M., Cunha, E. B., Li, X., Huang, Y. S., Dixon, D., and Eichenbaum, Z. (2010). Shr of group A streptococcus is a new type of composite NEAT protein involved in sequestering haem from methaemoglobin. Mol. Microbiol. 78, 739-756. doi: 10.1111/j.1365-2958.2010.07367.x

Owens, C. P., Chim, N., Graves, A. B., Harmston, C. A., Iniguez, A., Contreras, H., et al. (2013). The Mycobacterium tuberculosis secreted protein Rv0203 transfers heme to membrane proteins MmpL3 and MmpL11. J. Biol. Chem. 288, 21714-21728. doi: 10.1074/jbc.M113.453076

Owens, C. P., Du, J., Dawson, J. H., and Goulding, C. W. (2012). Characterization of heme ligation properties of Rv0203, a secreted heme binding protein involved in Mycobacterium tuberculosis heme uptake. Biochemistry 51, 1518-1531. doi: 10.1021/bi2018305

Pantopoulos, K., Porwal, S. K., Tartakoff, A., and Devireddy, L. (2012). Mechanisms of mammalian iron homeostasis. Biochemistry 51, 5705-5724. doi: 10.1021/bi300752r

Paquelin, A., Ghigo, J. M., Bertin, S., and Wandersman, C. (2001). Characterization of HasB, a Serratia marcescens TonB-like protein specifically involved in the haemophore-dependent haem acquisition system. Mol. Microbiol. 42, 995-1005. doi: 10.1046/j.1365-2958.2001.02628.x

Parker Siburt, C. J., Mietzner, T. A., and Crumbliss, A. L. (2012). FbpA-a bacterial transferrin with more to offer. Biochim. Biophys. Acta 1820, 379-392. doi: 10.1016/j.bbagen.2011.09.001

Pendrak, M. L., Chao, M. P., Yan, S. S., and Roberts, D. D. (2004). Heme oxygenase in Candida albicans is regulated by hemoglobin and is necessary for metabolism of exogenous heme and hemoglobin to alpha-biliverdin. J. Biol. Chem. 279, 3426-3433. doi: 10.1074/jbc.M311550200

Perkins-Balding, D., Baer, M. T., and Stojiljkovic, I. (2003). Identification of functionally important regions of a haemoglobin receptor from Neisseria meningitidis. Microbiology 149, 3423-3435. doi: 10.1099/mic.0.26448-0

Perry, R. D., Shah, J., Bearden, S. W., Thompson, J. M., and Fetherston, J. D. (2003). Yersinia pestis TonB: role in iron, heme, and hemoprotein utilization. Infect. Immun. 71, 4159-4162. doi: 10.1128/IAI.71.7.4159-4162.2003

Philpott, C. C., Leidgens, S., and Frey, A. G. (2012). Metabolic remodeling in iron-deficient fungi. Biochim. Biophys. Acta 1823, 1509-1520. doi: 10.1016/j.bbamcr.2012.01.012

Pierce, J. R., Pickett, C. L., and Earhart, C. F. (1983). Two fep genes are required for ferrienterochelin uptake in Escherichia coli K-12. J. Bacteriol. 155, 330-336.

Pilpa, R. M., Robson, S. A., Villareal, V. A., Wong, M. L., Phillips, M., and Clubb, R. T. (2009). Functionally distinct NEAT (NEAr Transporter) domains within the Staphylococcus aureus IsdH/HarA protein extract heme from methemoglobin. J. Biol. Chem. 284, 1166-1176. doi: 10.1074/jbc.M806007200

Pollack, J. R., and Neilands, J. B. (1970). Enterobactin, an iron transport compound from Salmonella typhimurium. Biochem. Biophys. Res. Commun. 38, 989-992.

Poole, K., Young, L., and Neshat, S. (1990). Enterobactin-mediated iron transport in Pseudomonas aeruginosa. J. Bacteriol. 172, 6991-6996.
Qiu, A., Jansen, M., Sakaris, A., Min, S. H., Chattopadhyay, S., Tsai, E., et al. (2006). Identification of an intestinal folate transporter and the molecular basis for hereditary folate malabsorption. Cell 127, 917-928. doi: 10.1016/j.cell.2006.09.041

Rajagopal, A., Rao, A. U., Amigo, J., Tian, M., Upadhyay, S. K., Hall, C., et al. (2008). Haem homeostasis is regulated by the conserved and concerted functions of HRG-1 proteins. Nature 453, 1127-1131. doi: 10.1038/nature06934

Ramanan, N., and Wang, Y. (2000). A high-affinity iron permease essential for Candida albicans virulence. Science 288, 1062-1064. doi: 10.1126/science.288.5468.1062

Ratliff, M., Zhu, W., Deshmukh, R., Wilks, A., and Stojilikovic, I. (2001). Homologues of neisserial heme oxygenase in gram-negative bacteria: degradation of heme by the product of the pigA gene of Pseudomonas aeruginosa. J. Bacteriol. 183, 6394-6403. doi: 10.1128/JB.183.21.6394-6403.2001

Raymond-Bouchard, I., Carroll, C. S., Nesbitt, J. R., Henry, K. A., Pinto, L. J., Moinzadeh, M., et al. (2012). Structural requirements for the activity of the MirB ferrisiderophore transporter of Aspergillus fumigatus. Eukaryot. Cell 11, 1333-1344. doi: 10.1128/EC.00159-12

Renauld-Mongenie, G., Poncet, D., Mignon, M., Fraysse, S., Chabanel, C., Danve, B., et al. (2004). Role of transferrin receptor from a Neisseria meningitidis tbpB isotype II strain in human transferrin binding and virulence. Infect. Immun. 72, 3461-3470. doi: 10.1128/IAI.72.6.3461-3470.2004

Robey, M., and Cianciotto, N. P. (2002). Legionella pneumophila feoAB promotes ferrous iron uptake and intracellular infection. Infect. Immun. 70, 5659-5669. doi: 10.1128/IAI.70.10.5659-5669.2002

Rohde, K. H., Gillaspy, A. F., Hatfield, M. D., Lewis, L. A., and Dyer, D. W. (2002). Interactions of haemoglobin with the Neisseria meningitidis receptor HpuAB: the role of TonB and an intact proton motive force. Mol. Microbiol. 43, 335-354. doi: 10.1046/j.1365-2958.2002.02745.x

Ronpirin, C., Jerse, A. E., and Cornelissen, C. N. (2001). Gonococcal genes encoding transferrin-binding proteins $\mathrm{A}$ and $\mathrm{B}$ are arranged in a bicistronic operon but are subject to differential expression. Infect. Immun. 69, 6336-6347. doi: 10.1128/IAI.69.10.6336-6347.2001

Rossi, M. S., Fetherston, J. D., Letoffe, S., Carniel, E., Perry, R. D., and Ghigo, J. M. (2001). Identification and characterization of the hemophore-dependent heme acquisition system of Yersinia pestis. Infect. Immun. 69, 6707-6717. doi: 10.1128/IAI.69.11.6707-6717.2001

Rossi, M. S., Paquelin, A., Ghigo, J. M., and Wandersman, C. (2003). Haemophore-mediated signal transduction across the bacterial cell envelope in Serratia marcescens: the inducer and the transported substrate are different molecules. Mol. Microbiol. 48, 1467-1480. doi: 10.1046/j.1365-2958.2003. 03516.x

Rouault, T. A., and Tong, W. H. (2008). Iron-sulfur cluster biogenesis and human disease. Trends Genet. 24, 398-407. doi: 10.1016/j.tig.2008.05.008

Runyen-Janecky, L. J., Reeves, S. A., Gonzales, E. G., and Payne, S. M. (2003). Contribution of the Shigella flexneri Sit, Iuc, and Feo iron acquisition systems to iron acquisition in vitro and in cultured cells. Infect. Immun. 71, 1919-1928. doi: 10.1128/IAI.71.4.1919-1928.2003

Salvail, H., and Masse, E. (2012). Regulating iron storage and metabolism with RNA: an overview of posttranscriptional controls of intracellular iron homeostasis. Wiley Interdiscip. Rev. RNA 3, 26-36. doi: 10.1002/wrna.102

Sandrini, S. M., Shergill, R., Woodward, J., Muralikuttan, R., Haigh, R. D., Lyte, M., et al. (2010). Elucidation of the mechanism by which catecholamine stress hormones liberate iron from the innate immune defense proteins transferrin and lactoferrin. J. Bacteriol. 192, 587-594. doi: 10.1128/JB.01028-09

Schade, A. L., and Caroline, L. (1944). Raw hen egg white and the role of iron in growth inhibition of shigella dysenteriae, Staphylococcus Aureus, Escherichia Coli and Saccharomyces Cerevisiae. Science 100, 14-15. doi: 10.1126/science.100.2584.14

Schalk, I. J., and Guillon, L. (2013). Fate of ferrisiderophores after import across bacterial outer membranes: different iron release strategies are observed in the cytoplasm or periplasm depending on the siderophore pathways. Amino Acids 44, 1267-1277. doi: 10.1007/s00726-013-1468-2

Schrettl, M., Bignell, E., Kragl, C., Joechl, C., Rogers, T., Arst, H. N. Jr., et al. (2004). Siderophore biosynthesis but not reductive iron assimilation is essential for Aspergillus fumigatus virulence. J. Exp. Med. 200, 1213-1219. doi: 10.1084/jem.20041242 
Schrettl, M., Bignell, E., Kragl, C., Sabiha, Y., Loss, O., Eisendle, M., et al. (2007). Distinct roles for intra- and extracellular siderophores during Aspergillus fumigatus infection. PLoS Pathog. 3:e128. doi: 10.1371/journal.ppat.0030128

Schrettl, M., and Haas, H. (2011). Iron homeostasis-Achilles' heel of Aspergillus fumigatus? Curr. Opin. Microbiol. 14, 400-405. doi: 10.1016/j.mib.2011.06.002

Seale, T. W., Morton, D. J., Whitby, P. W., Wolf, R., Kosanke, S. D., Vanwagoner, T. M., et al. (2006). Complex role of hemoglobin and hemoglobin-haptoglobin binding proteins in Haemophilus influenzae virulence in the infant rat model of invasive infection. Infect. Immun. 74, 6213-6225. doi: 10.1128/IAI.00744-06

Sebulsky, M. T., and Heinrichs, D. E. (2001). Identification and characterization of fhuD1 and fhuD2, two genes involved in iron-hydroxamate uptake in Staphylococcus aureus. J. Bacteriol. 183, 4994-5000. doi: 10.1128/JB.183.17.4994-5000.2001

Sebulsky, M. T., Hohnstein, D., Hunter, M. D., and Heinrichs, D. E. (2000). Identification and characterization of a membrane permease involved in ironhydroxamate transport in Staphylococcus aureus. J. Bacteriol. 182, 4394-4400. doi: 10.1128/JB.182.16.4394-4400.2000

Sebulsky, M. T., Shilton, B. H., Speziali, C. D., and Heinrichs, D. E. (2003). The role of FhuD2 in iron(III)-hydroxamate transport in Staphylococcus aureus. Demonstration that FhuD2 binds iron(III)-hydroxamates but with minimal conformational change and implication of mutations on transport. J. Biol. Chem. 278, 49890-49900. doi: 10.1074/jbc.M305073200

Senesi, S., and Ghelardi, E. (2010). Production, secretion and biological activity of Bacillus cereus enterotoxins. Toxins (Basel) 2, 1690-1703. doi: 10.3390/toxins 2071690

Shayeghi, M., Latunde-Dada, G. O., Oakhill, J. S., Laftah, A. H., Takeuchi, K., Halliday, N., et al. (2005). Identification of an intestinal heme transporter. Cell 122, 789-801. doi: 10.1016/j.cell.2005.06.025

Shea, C. M., and McIntosh, M. A. (1991). Nucleotide sequence and genetic organization of the ferric enterobactin transport system: homology to other periplasmic binding protein-dependent systems in Escherichia coli. Mol. Microbiol. 5, 1415-1428. doi: 10.1111/j.1365-2958.1991.tb00788.x

Siburt, C. J., Roulhac, P. L., Weaver, K. D., Noto, J. M., Mietzner, T. A., Cornelissen, C. N., et al. (2009). Hijacking transferrin bound iron: protein-receptor interactions involved in iron transport in N. gonorrhoeae. Metallomics 1, 249-255. doi: $10.1039 / \mathrm{b} 902860 \mathrm{a}$

Simon, N., Coulanges, V., Andre, P., and Vidon, D. J. (1995). Utilization of exogenous siderophores and natural catechols by Listeria monocytogenes. Appl. Environ. Microbiol. 61, 1643-1645.

Simpson, W., Olczak, T., and Genco, C. A. (2000). Characterization and expression of HmuR, a TonB-dependent hemoglobin receptor of Porphyromonas gingivalis. J. Bacteriol. 182, 5737-5748. doi: 10.1128/JB.182.20.57375748.2000

Skaar, E. P., Humayun, M., Bae, T., Debord, K. L., and Schneewind, O. (2004). Ironsource preference of Staphylococcus aureus infections. Science 305, 1626-1628. doi: 10.1126/science.1099930

Smalley, J. W., Birss, A. J., Szmigielski, B., and Potempa, J. (2007). Sequential action of R- and K-specific gingipains of Porphyromonas gingivalis in the generation of the haem-containing pigment from oxyhaemoglobin. Arch. Biochem. Biophys. 465, 44-49. doi: 10.1016/j.abb.2007.05.011

Smalley, J. W., Byrne, D. P., Birss, A. J., Wojtowicz, H., Sroka, A., Potempa, J., et al. (2011). HmuY haemophore and gingipain proteases constitute a unique syntrophic system of haem acquisition by Porphyromonas gingivalis. PLoS ONE 6:e17182. doi: 10.1371/journal.pone.0017182

Snow, G. A. (1954). Mycobactin. A growth factor for Mycobacterium johnei. Part III. Degradation and tentative structure. J. Chem. Soc. 1954, 4080-4093. doi: 10.1039/jr9540004080

Speziali, C. D., Dale, S. E., Henderson, J. A., Vines, E. D., and Heinrichs, D. E. (2006). Requirement of Staphylococcus aureus ATP-binding cassette-ATPase FhuC for iron-restricted growth and evidence that it functions with more than one iron transporter. J. Bacteriol. 188, 2048-2055. doi: 10.1128/JB.188.6.20482055.2006

Spiro, S., and Guest, J. R. (1990). FNR and its role in oxygen-regulated gene expression in Escherichia coli. FEMS Microbiol. Rev. 6, 399-428. doi: 10.1016/S01686445(05)80007-5

Sprencel, C., Cao, Z., Qi, Z., Scott, D. C., Montague, M. A., Ivanoff, N., et al. (2000). Binding of ferric enterobactin by the Escherichia coli periplasmic protein FepB. J. Bacteriol. 182, 5359-5364. doi: 10.1128/JB.182.19.5359-5364.2000
Sridhar, S., Ahluwalia, M., Brummer, E., and Stevens, D. A. (2000). Characterization of an anticryptococcal protein isolated from human serum. Infect. Immun. 68, 3787-3791. doi: 10.1128/IAI.68.6.3787-3791.2000

Steere, A. N., Byrne, S. L., Chasteen, N. D., and Mason, A. B. (2012). Kinetics of iron release from transferrin bound to the transferrin receptor at endosomal pH. Biochim. Biophys. Acta 1820, 326-333. doi: 10.1016/j.bbagen.2011. 06.003

Stoebner, J. A., and Payne, S. M. (1988). Iron-regulated hemolysin production and utilization of heme and hemoglobin by Vibrio cholerae. Infect. Immun. 56, 2891-2895.

Stojiljkovic, I., and Hantke, K. (1992). Hemin uptake system of Yersinia enterocolitica: similarities with other TonB-dependent systems in gram-negative bacteria. EMBO J. 11, 4359-4367.

Stojiljkovic, I., and Hantke, K. (1994). Transport of haemin across the cytoplasmic membrane through a haemin-specific periplasmic binding-protein-dependent transport system in Yersinia enterocolitica. Mol. Microbiol. 13, 719-732. doi: 10.1111/j.1365-2958.1994.tb00465.x

Stojiljkovic, I., Hwa, V., De Saint Martin, L., O’gaora, P, Nassif, X., Heffron, F., and So, M. (1995). The Neisseria meningitidis haemoglobin receptor: its role in iron utilization and virulence. Mol. Microbiol. 15, 531-541. doi: 10.1111/j.13652958.1995.tb02266.x

Strange, H. R., Zola, T. A., and Cornelissen, C. N. (2011). The fbpABC operon is required for Ton-independent utilization of xenosiderophores by Neisseria gonorrhoeae strain FA19. Infect. Immun. 79, 267-278. doi: 10.1128/IAI.00807-10

Takase, H., Nitanai, H., Hoshino, K., and Otani, T. (2000). Impact of siderophore production on Pseudomonas aeruginosa infections in immunosuppressed mice. Infect. Immun. 68, 1834-1839. doi: 10.1128/IAI.68.4.1834-1839.2000

Tandara, L., and Salamunic, I. (2012). Iron metabolism: current facts and future directions. Biochem. Med. (Zagreb) 22, 311-328. doi: 10.11613/BM.2012.034

Tangen, K. L., Jung, W. H., Sham, A. P., Lian, T., and Kronstad, J. W. (2007). The iron- and cAMP-regulated gene SIT1 influences ferrioxamine B utilization, melanization and cell wall structure in Cryptococcus neoformans. Microbiology 153, 29-41. doi: 10.1099/mic.0.2006/000927-0

Tauseef, I., Harrison, O. B., Wooldridge, K. G., Feavers, I. M., Neal, K. R., Gray, S. J., et al. (2011). Influence of the combination and phase variation status of the haemoglobin receptors $\mathrm{HmbR}$ and $\mathrm{HpuAB}$ on meningococcal virulence. Microbiology 157, 1446-1456. doi: 10.1099/mic.0.046946-0

Thomas-Charles, C. A., Zheng, H., Palmer, L. E., Mena, P., Thanassi, D. G., and Furie, M. B. (2013). FeoB-Mediated Uptake of Iron by Francisella tularensis. Infect. Immun. 81, 2828-2837. doi: 10.1128/IAI.00170-13

Thompson, J. M., Jones, H. A., and Perry, R. D. (1999). Molecular characterization of the hemin uptake locus (hmu) from Yersinia pestis and analysis of $\mathrm{hmu}$ mutants for hemin and hemoprotein utilization. Infect. Immun. 67, 3879-3892.

Tong, Y., and Guo, M. (2007). Cloning and characterization of a novel periplasmic heme-transport protein from the human pathogen Pseudomonas aeruginosa. J. Biol. Inorg. Chem. 12, 735-750. doi: 10.1007/s00775-007-0226-x

Torres, A. G., and Payne, S. M. (1997). Haem iron-transport system in enterohaemorrhagic Escherichia coli O157:H7. Mol. Microbiol. 23, 825-833. doi: 10.1046/j.1365-2958.1997.2641628.x

Torres, A. G., Redford, P., Welch, R. A., and Payne, S. M. (2001). TonB-dependent systems of uropathogenic Escherichia coli: aerobactin and heme transport and TonB are required for virulence in the mouse. Infect. Immun. 69, 6179-6185. doi: 10.1128/IAI.69.10.6179-6185.2001

Torres, V. J., Pishchany, G., Humayun, M., Schneewind, O., and Skaar, E. P. (2006). Staphylococcus aureus $\mathrm{IsdB}$ is a hemoglobin receptor required for heme iron utilization. J. Bacteriol. 188, 8421-8429. doi: 10.1128/JB.01335-06

Tullius, M. V., Harmston, C. A., Owens, C. P., Chim, N., Morse, R. P., McMath, L. M., et al. (2011). Discovery and characterization of a unique mycobacterial heme acquisition system. Proc. Natl. Acad. Sci. U.S.A. 108, 5051-5056. doi: 10.1073/pnas. 1009516108

Turner, P. C., Thomas, C. E., Elkins, C., Clary, S., and Sparling, P. F. (1998). Neisseria gonorrhoeae heme biosynthetic mutants utilize heme and hemoglobin as a heme source but fail to grow within epithelial cells. Infect. Immun. 66, 5215-5223.

Verdon, J., Girardin, N., Lacombe, C., Berjeaud, J. M., and Hechard, Y. (2009). delta-hemolysin, an update on a membrane-interacting peptide. Peptides 30, 817-823. doi: 10.1016/j.peptides.2008.12.017

Vulpe, C. D., Kuo, Y. M., Murphy, T. L., Cowley, L., Askwith, C., Libina, N., et al. (1999). Hephaestin, a ceruloplasmin homologue implicated in intestinal 
iron transport, is defective in the sla mouse. Nat. Genet. 21, 195-199. doi: $10.1038 / 5979$

Wallner, A., Blatzer, M., Schrettl, M., Sarg, B., Lindner, H., and Haas, H. (2009). Ferricrocin, a siderophore involved in intra- and transcellular iron distribution in Aspergillus fumigatus. Appl. Environ. Microbiol. 75, 4194-4196. doi: 10.1128/ AEM.00479-09

Wandersman, C., and Delepelaire, P. (2004). Bacterial iron sources: from siderophores to hemophores. Annu. Rev. Microbiol. 58, 611-647. doi: 10.1146/ annurev.micro.58.030603.123811

Wandersman, C., and Delepelaire, P. (2012). Haemophore functions revisited. Mol. Microbiol. 85, 618-631. doi: 10.1111/j.1365-2958.2012.08136.x

Wang, J., and Pantopoulos, K. (2011). Regulation of cellular iron metabolism. Biochem. J. 434, 365-381. doi: 10.1042/BJ20101825

Watanabe, T., Takano, M., Murakami, M., Tanaka, H., Matsuhisa, A., Nakao, N., et al. (1999). Characterization of a haemolytic factor from Candida albicans. Microbiology 145(Pt 3), 689-694. doi: 10.1099/13500872-145-3-689

Weissman, Z., and Kornitzer, D. (2004). A family of Candida cell surface haembinding proteins involved in haemin and haemoglobin-iron utilization. Mol. Microbiol. 53, 1209-1220. doi: 10.1111/j.1365-2958.2004.04199.x

Weissman, Z., Shemer, R., Conibear, E., and Kornitzer, D. (2008). An endocytic mechanism for haemoglobin-iron acquisition in Candida albicans. Mol. Microbiol. 69, 201-217. doi: 10.1111/j.1365-2958.2008.06277.x

Wilks, A., and Schmitt, M. P. (1998). Expression and characterization of a heme oxygenase (Hmu O) from Corynebacterium diphtheriae. Iron acquisition requires oxidative cleavage of the heme macrocycle. J. Biol. Chem. 273, 837-841. doi: $10.1074 /$ jbc.273.2.837

Williams, J., and Moreton, K. (1980). The distribution of iron between the metalbinding sites of transferrin human serum. Biochem. J. 185, 483-488.

Winkelmann, G. (2002). Microbial siderophore-mediated transport. Biochem. Soc. Trans. 30, 691-696. doi: 10.1042/BST0300691

Winkelmann, G. (2007). Ecology of siderophores with special reference to the fungi. Biometals 20, 379-392. doi: 10.1007/s10534-006-9076-1

Wojtowicz, H., Guevara, T., Tallant, C., Olczak, M., Sroka, A., Potempa, J., et al. (2009). Unique structure and stability of HmuY, a novel heme-binding protein of Porphyromonas gingivalis. PLoS Pathog. 5:e1000419. doi: 10.1371/journal.ppat.1000419

Wong, J. C., Patel, R., Kendall, D., Whitby, P. W., Smith, A., Holland, J., et al. (1995). Affinity, conservation, and surface exposure of hemopexin-binding proteins in Haemophilus influenzae. Infect. Immun. 63, 2327-2333.

Wooldridge, K. G., Morrissey, J. A., and Williams, P. H. (1992). Transport of ferricaerobactin into the periplasm and cytoplasm of Escherichia coli K12: role of envelope-associated proteins and effect of endogenous siderophores. J. Gen. Microbiol. 138, 597-603. doi: 10.1099/00221287-138-3-597

Wu, J., Lin, X., and Xie, H. (2009). Regulation of hemin binding proteins by a novel transcriptional activator in Porphyromonas gingivalis. J. Bacteriol. 191, 115-122. doi: 10.1128/JB.00841-08

Wu, R., Skaar, E. P., Zhang, R., Joachimiak, G., Gornicki, P., Schneewind, O., et al. (2005). Staphylococcus aureus IsdG and IsdI, heme-degrading enzymes with structural similarity to monooxygenases. J. Biol. Chem. 280, 2840-2846. doi: 10.1074/jbc.M409526200

Wyckoff, E. E., Boulette, M. L., and Payne, S. M. (2009). Genetics and environmental regulation of Shigella iron transport systems. Biometals 22, 43-51. doi: 10.1007/s10534-008-9188-x
Yanatori, I., Tabuchi, M., Kawai, Y., Yasui, Y., Akagi, R., and Kishi, F. (2010). Heme and non-heme iron transporters in non-polarized and polarized cells. BMC Cell Biol. 11:39. doi: 10.1186/1471-2121-11-39

Yang, F., Naylor, S. L., Lum, J. B., Cutshaw, S., McCombs, J. L., Naberhaus, K. H., et al. (1986). Characterization, mapping, and expression of the human ceruloplasmin gene. Proc. Natl. Acad. Sci. U.S.A. 83, 3257-3261. doi: $10.1073 /$ pnas.83.10.3257

Yokota, K., Shimada, H., Kamaguchi, A., and Sakaguchi, O. (1977). Studies on the toxin of Aspergillus fumigatus. VII. Purification and some properities of hemolytic toxin (asp-hemolysin) from culture filtrates and mycelia. Microbiol. Immunol. 21, 11-22.

Yoo Ji, J., Lee, Y. S., Song, C. Y., and Kim, B. S. (2004). Purification and characterization of a 43-kilodalton extracellular serine proteinase from Cryptococcus neoformans. J. Clin. Microbiol. 42, 722-726. doi: 10.1128/JCM.42.2.722-726.2004

Zalkin, A., Forrester, J. D., and Templeton, D. H. (1964). Crystal and molecular structure of ferrichrome A. Science 146, 261-263. doi: 10.1126/science.146.3641.261

Zhu, H., Xie, G., Liu, M., Olson, J. S., Fabian, M., Dooley, D. M., et al. (2008). Pathway for heme uptake from human methemoglobin by the iron-regulated surface determinants system of Staphylococcus aureus. J. Biol. Chem. 283, 18450-18460. doi: 10.1074/jbc.M801466200

Zhu, M., Valdebenito, M., Winkelmann, G., and Hantke, K. (2005). Functions of the siderophore esterases IroD and IroE in iron-salmochelin utilization. Microbiology 151, 2363-2372. doi: 10.1099/mic.0.27888-0

Zhu, W., Hunt, D. J., Richardson, A. R., and Stojiljkovic, I. (2000a). Use of heme compounds as iron sources by pathogenic neisseriae requires the product of the hemO gene. J. Bacteriol. 182, 439-447. doi: 10.1128/JB.182.2.439-447.2000

Zhu, W., Wilks, A., and Stojiljkovic, I. (2000b). Degradation of heme in gram-negative bacteria: the product of the hemO gene of Neisseriae is a heme oxygenase. J. Bacteriol. 182, 6783-6790. doi: 10.1128/JB.182.23.67836790.2000

Ziegler, L., Terzulli, A., Gaur, R., McCarthy, R., and Kosman, D. J. (2011). Functional characterization of the ferroxidase, permease high-affinity iron transport complex from Candida albicans. Mol. Microbiol. 81, 473-485. doi: 10.1111/j.1365-2958.2011.07704.x

Conflict of Interest Statement: The authors declare that the research was conducted in the absence of any commercial or financial relationships that could be construed as a potential conflict of interest.

Received: 11 August 2013; accepted: 30 October 2013; published online: 19 November 2013.

Citation: Caza M and Kronstad JW (2013) Shared and distinct mechanisms of iron acquisition by bacterial and fungal pathogens of humans. Front. Cell. Infect. Microbiol. 3:80. doi: $10.3389 / f_{\text {cimb.2013.00080 }}$

This article was submitted to the journal Frontiers in Cellular and Infection Microbiology.

Copyright (c) 2013 Caza and Kronstad. This is an open-access article distributed under the terms of the Creative Commons Attribution License (CC BY). The use, distribution or reproduction in other forums is permitted, provided the original author(s) or licensor are credited and that the original publication in this journal is cited, in accordance with accepted academic practice. No use, distribution or reproduction is permitted which does not comply with these terms. 